ARTICLE

\title{
Modeling early stage atherosclerosis in a primary human vascular microphysiological system
}

Xu Zhang ${ }^{1}$, Muath Bishawi (10) ${ }^{1,2}$, Ge Zhang $^{3,4}$, Varun Prasad ${ }^{1}$, Ellen Salmon ${ }^{1}$, Jason J. Breithaupt ${ }^{1,5}$, Qiao Zhang ${ }^{1}$ \& George A. Truskey (10) ${ }^{1 凶}$

Novel atherosclerosis models are needed to guide clinical therapy. Here, we report an in vitro model of early atherosclerosis by fabricating and perfusing multi-layer arteriole-scale human tissue-engineered blood vessels (TEBVs) by plastic compression. TEBVs maintain mechanical strength, vasoactivity, and nitric oxide (NO) production for at least 4 weeks. Perfusion of TEBVs at a physiological shear stress with enzyme-modified low-density-lipoprotein (eLDL) with or without TNF $\alpha$ promotes monocyte accumulation, reduces vasoactivity, alters NO production, which leads to endothelial cell activation, monocyte accumulation, foam cell formation and expression of pro-inflammatory cytokines. Removing eLDL leads to recovery of vasoactivity, but not loss of foam cells or recovery of permeability, while pretreatment with lovastatin or the $\mathrm{P} 2 \mathrm{Y}_{11}$ inhibitor NF157 reduces monocyte accumulation and blocks foam cell formation. Perfusion with blood leads to increased monocyte adhesion. This atherosclerosis model can identify the role of drugs on specific vascular functions that cannot be assessed in vivo.

\footnotetext{
${ }^{1}$ Department of Biomedical Engineering, Duke University, Durham, NC 27708, USA. ${ }^{2}$ Division of Cardiothoracic Surgery, Department of Surgery, Duke University, Durham, NC 27708, USA. ${ }^{3}$ Department of Immunology, College of Basic Medical Science, Dalian Medical University, 116044 Dalian, China. ${ }^{4}$ Department of Microbiology and Immunology, School of Medicine, University of North Carolina at Chapel Hill, Chapel Hill, NC 27599, USA. ${ }^{5}$ University of Miami Miller School of Medicine, Miami, FL 33163, USA. ${ }^{凶}$ email: gtruskey@duke.edu
} 
$\mathrm{T}$ he pathogenesis of atherosclerosis involves the accumulation of cholesterol containing low-density lipoprotein (LDL) in the arterial wall interacting with risk factors (e.g. smoking, hypertension). Subsequent free radical generation leads to lesion formation ${ }^{1,2}$. The oxidative environment activates vascular endothelial cells (ECs) as evidenced by increased expression of endothelial adhesion molecules and reduced vasodilation in response to increased blood flow ${ }^{3}$. Plasma LDL undergoes a series of modifications and accumulates in the intima ${ }^{4}$ (Fig. 1a). Eventually monocytes enter and differentiate into macrophages, joined by proliferation of resident macrophages ${ }^{4,5}$. This is a critical step in the process, as this pool of macrophages accumulate cholesterol from modified LDL in an unregulated fashion by scavenger receptors, forming foam cells ${ }^{2,6}$. Medial smooth muscle cells (SMCs) migrate and proliferate in the intima and also form foam cells $s^{1,2}$.

Inflammation plays an important role in the development and clinical presentation of atherosclerosis ${ }^{7,8}$, and significantly higher rates of atherosclerosis occur in individuals with autoimmune disease, such as rheumatoid arthritis (RA $)^{9-11}$. The recent CANTOS trial demonstrated that cardiac events and death due to atherosclerosis are reduced by an antibody to IL- $1 \beta$, which is used to treat $\mathrm{RA}^{12}$ and the COLCOT study showed that the inexpensive anti-inflammatory compound colchicine leads to reduced inflammation and fewer adverse cardiovascular events ${ }^{13}$. These studies emphasize the potential of anti-inflammatory treatments to reduce clinical complications of atherosclerosis, but other antiinflammatory treatments have not been effective ${ }^{14}$. Thus, there is a need to establish those immune pathways that can reduce clinical symptoms and aid regression of the disease.

Mechanisms of the initiation and progression of atherosclerosis have largely been studied using animal models ${ }^{15,16}$. These animal models however suffer from a number of limitations including important differences in disease progression than that seen in humans, lack of external validation of the results to humans, expense and long duration to assess disease progression, and the difficulty of isolating the many factors involved in such a complex disease $^{17,18}$. Human microphysiological systems (MPS) have been introduced to address many of these pitfalls and to examine the effect of genetic variants in disease development ${ }^{19,20}$.

There are three types of vascular MPS: (1) microvascular systems that focus on self-organization to form vascular networks in ECM (extra-cellular matrix) and stromal cells for vascular development and related disease studies ${ }^{21-25}$; (2) microfluidic vascular chips that mimic the vascular lumen through culture of the ECs in well-designed flow channels, to examine interaction of ECs with other cells and thrombosis ${ }^{21,26-28}$; and (3) tissueengineered blood vessels (TEBVs) consisting of intimal and medial layers to study drug responses and model arterial diseases $^{29-31}$. While some of the other vascular models included endothelial cells and medial cells, only the TEBV examined endothelial cell-medial cell interactions on vascular function in vitro ${ }^{29-31}$.

In this work, we extend our human TEBV model and use it to simulate many key features in early atherosclerosis. We create a chip to fabricate and perfuse four TEBVs simultaneously and develop a three-layer model of ECs, SMCs, and fibroblasts. Endothelial dysfunction is an early step in atherosclerosis and plays a central role in many vascular-related disorders ${ }^{32-34}$. Similar to natural blood vessels, functional properties of tissueengineered vessels are highly dependent on the endothelial layer ${ }^{35,36}$. Therefore, endothelization of TEBVs is important for the overall utility of this model, and examination of the impact of their functional properties ${ }^{29,31,37,38}$.

To create a model of early stage atherosclerosis and examine the effect of drug treatments, we exposed human TEBVs to enzyme-modified low-density lipoprotein (eLDL) (Fig.1a). The TEBVs are then tested in the presence of eLDL, the cytokine tumor necrosis factor $\alpha(\mathrm{TNF} \alpha)$, and the addition of circulating monocytes in cell media or human whole blood with notable changes in vasoactivity, permeability, endothelial activation, as well as monocyte accumulation and foam cell formation in the vessel wall, all important hallmarks of early atherosclerosis. Many of these short-term pro-inflammatory events are reversible in vitro and these early atherosclerotic events can be reduced with drug treatments.

\section{Results}

Fabrication and characterization of TEBVs. Four TEBVs with 2 layers or 3 layers were fabricated simultaneously in situ in one chip using different parts of the mold (Fig. S1). To enhance the overall concentration of collagen and improve the mechanical properties of TEBVs, application of plastic compression removed over $90 \%$ of the water (Fig. S2). The final concentration of collagen in the TEBVs was $70 \mathrm{mg} / \mathrm{ml}$, which is similar to the value in vessels in vivo ${ }^{39}$. Final TEBV dimensions were $>10 \mathrm{~mm}$ in length and $1074 \pm 99 \mu \mathrm{m}(n=4)$ in outer diameter. For the EC/fibroblast 2-layer TEBV, the lumen was circular with an internal diameter of $647.5 \pm 45.7 \mu \mathrm{m}(n=4)$. The vessel wall had a mean thickness of $210 \mu \mathrm{m}$ (Fig. 1c). Cross-sectional images demonstrate a wellformed endothelial cell layer (evident by CD31 staining) defining the vessel lumen, with hNDFs \pm hSMCs distributed uniformly in vessel wall (Fig. 1d). En face (Fig. 1e) and 3D reconstructions of the TEBV (Fig. 1f) demonstrate good endothelial coverage. Furthermore, the collagen TEBV does not permit fluid extravasation as shown by perfusion of a dye through the lumen (Supplementary Movie 1).

While primary human SMCs are most relevant to accurately mimic human blood vessels, they suffer from several shortcomings including limited proliferative capacity and donor availability, and significant donor to donor variation ${ }^{40}$. Often donors are older and have cardiovascular disease resulting in SMCs with reduced contractility ${ }^{4}$. TEBVs fabricated with hNDFs are significantly more contractile than those fabricated from $\mathrm{MSCs}^{31}$ and still express the key proteins calponin and aSMA. In 3-layer TEBVs, the layers of EC, SMC, and fibroblast were clearly distinguished (Fig. 1g), and the total medial thickness was similar to the value for the two-layer model and the inner hSMC layer $(75.5 \pm 10.6 \mu \mathrm{m}$ (mean \pm S.D. $))$ was about half the thickness of the outer hNDF layer, even though the same number of hSMCs and hNDFs were initially seeded into the collagen solution. In the 3-layer TEBVs, both hNDFs and hSMCs expressed smooth muscle-related markers aSMA and MHC11 both in cross-sections (Fig. S3a, b) and longitudinal sections (Fig. S3c).

TEBV properties and function after perfusion. Perfusion began within $24 \mathrm{~h}$ of fabrication at a flow rate of $0.5 \mathrm{ml} / \mathrm{min}$ per TEBV (0.4 Pa shear stress). The burst pressure after dehydration, $1.036 \pm 0.006$ bar, increased to $1.61 \pm 0.03$ bar after one week of perfusion and was relatively constant for the next 3 weeks (Fig. 2a). The ultimate tensile stress of the TEBVs was as high as 12-15 bar and was stable for at least 4 weeks (Fig. 2b). After one week of perfusion, TEBVs exhibited phenylephrine-induced vasoconstriction and acetylcholine-induced vasodilation (Fig. 2c), which were maintained over 4 weeks of perfusion. After $48 \mathrm{~h}$ perfusion nitric oxide (NO) production of nitrate and nitrite was about $20 \mu \mathrm{M}$ in the perfusion media (Fig. 2d) and was maintained over four weeks. Endothelial release of NO further demonstrates maturation of TEBVs after 1 week of perfusion. Furthermore, the TEBV diameter is stable over time with changes in the diameter of less than $\pm 5 \%$ with no consistent trend (Fig. 2e). 
a (i) $\frac{-2}{-\infty}$ (Q)
( )
(2)

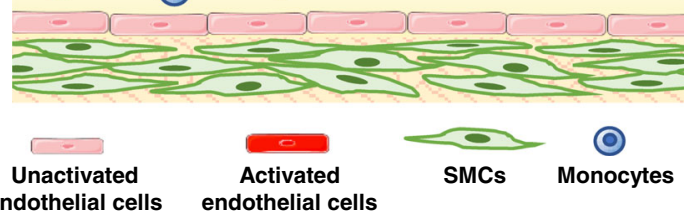
( )

ㅇ

b

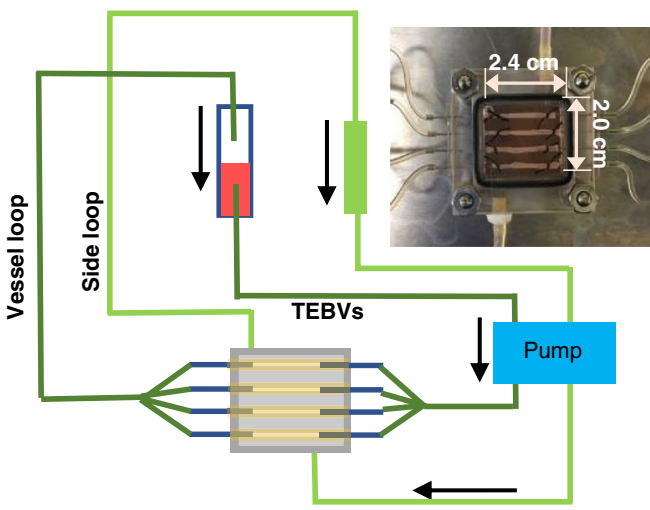

(ii)

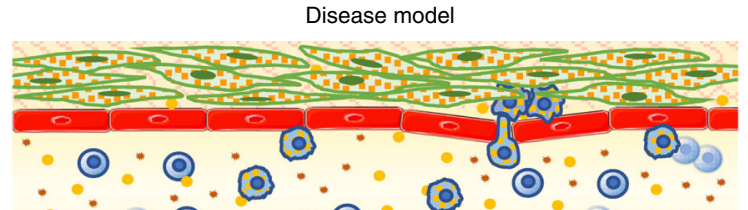

()
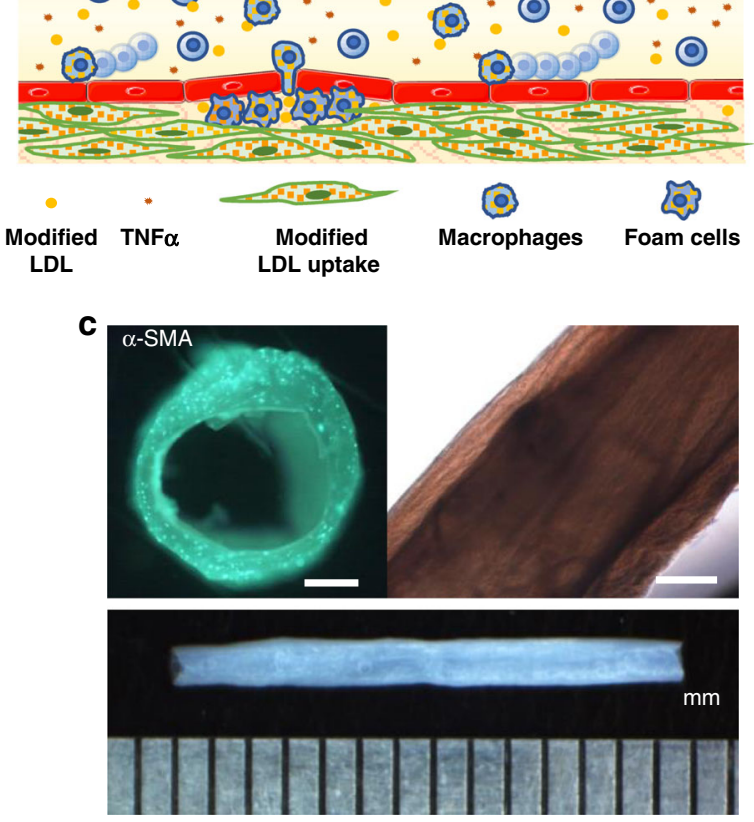

d
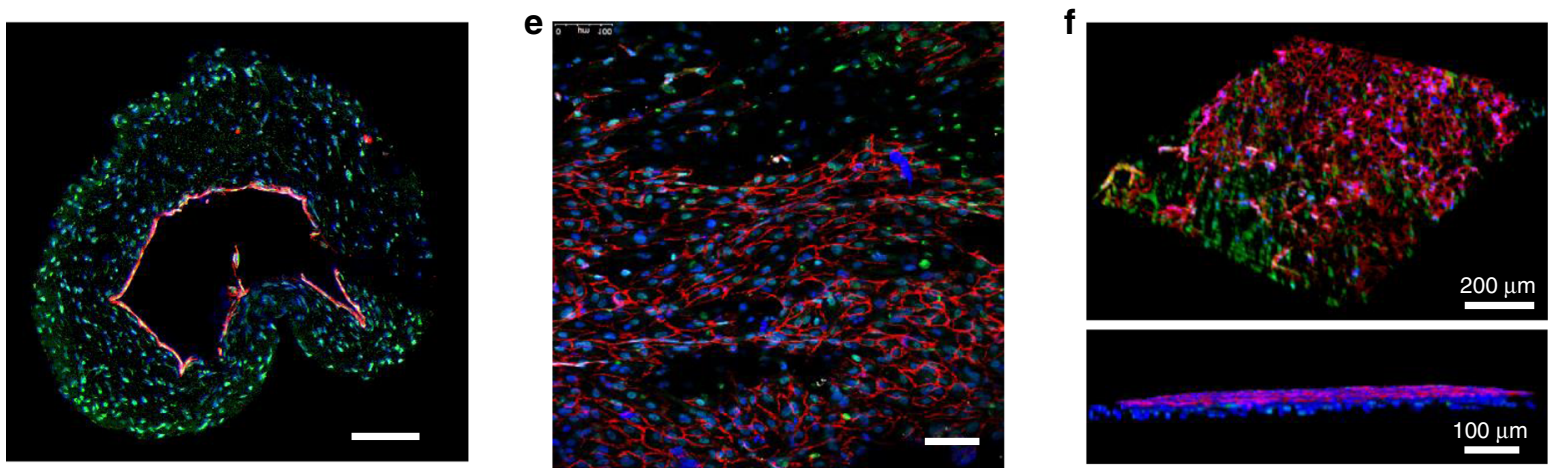

g
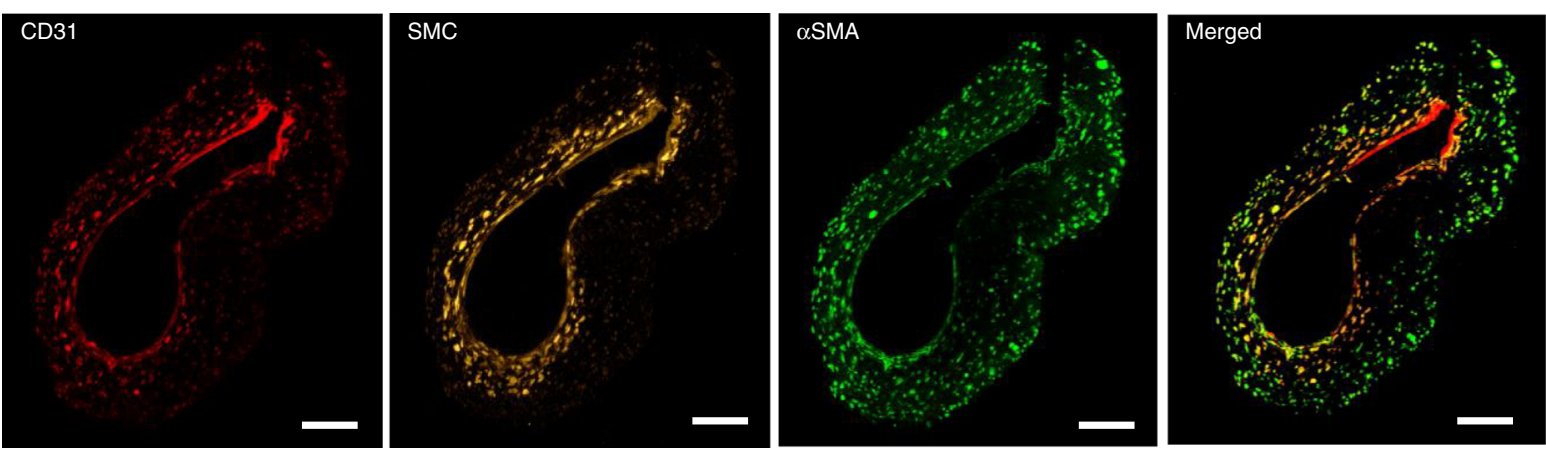

Fig. 1 Fabrication and characterization of tissue-engineered blood vessels (TEBVs.). a Under healthy conditions (i), monocytes do not adhere to the endothelium. Under disease conditions (ii), modified forms of LDL (low-density lipoprotein), or cytokines such as TNF $\alpha$, activate the endothelium to increase expression of leukocyte adhesion molecules and release cytokines that enable monocytes to adhere to the endothelium and transmigrate into the media. Modified LDL in the media is taken up by monocytes/macrophages and hSMCs (human smooth muscle cells) becoming foam cells. $\mathbf{b}$ Schematic diagram of the perfusion system. c Bright-field views of TEBV. Scale bar $=200 \mu \mathrm{m}$. d Cross-sectional view of 2-layer TEBV showing an intact CD31 positive endothelium; Scale bar $=200 \mu \mathrm{m}$. e En face view of lumen showing CD31 positive endothelium overlying $\alpha$ SMA positive hNDF; Scale bar $=100 \mu \mathrm{m}$. f 3D view of opened TEBV (d-f: CD31-red, $\alpha$ SMA-green, DAPI-blue). $\mathbf{g}$ Cross-sectional view of 3-layer TEBV: endothelial layer (CD31-red), smooth muscle cell layer (cell tracker-yellow), fibroblast layer ( $\alpha$ SMA-green); Scale bar $=200 \mu \mathrm{m}$. 


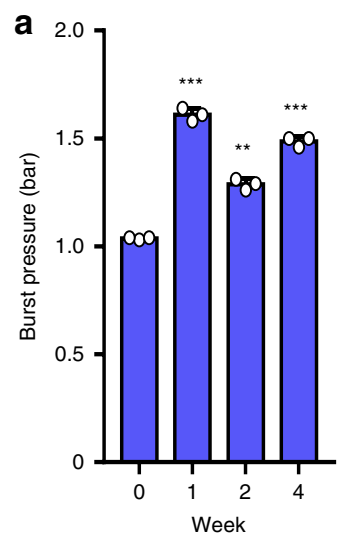

e

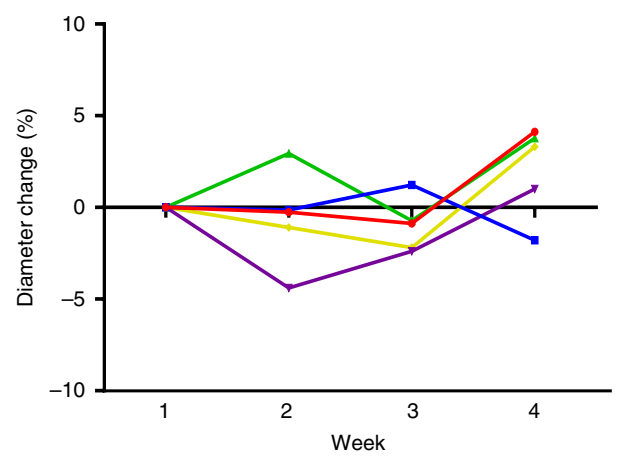

g

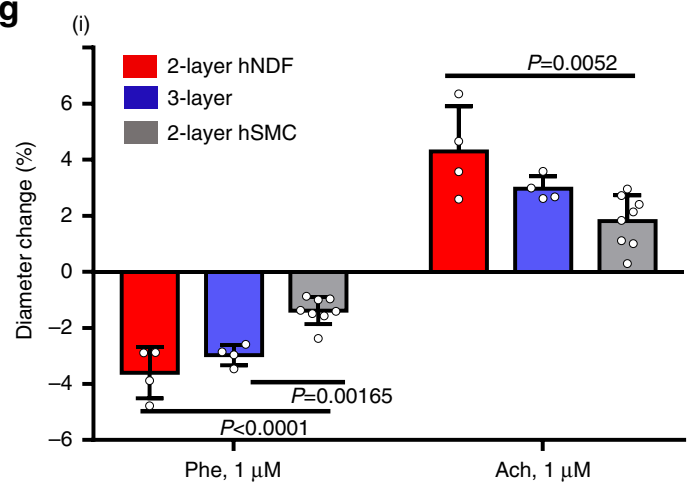

$\mathbf{f}$
C

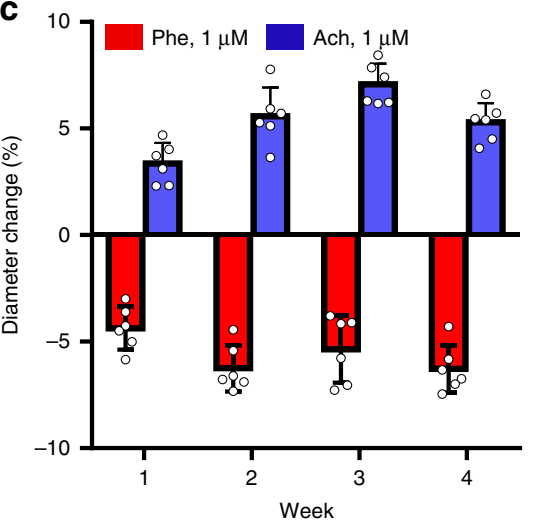

d

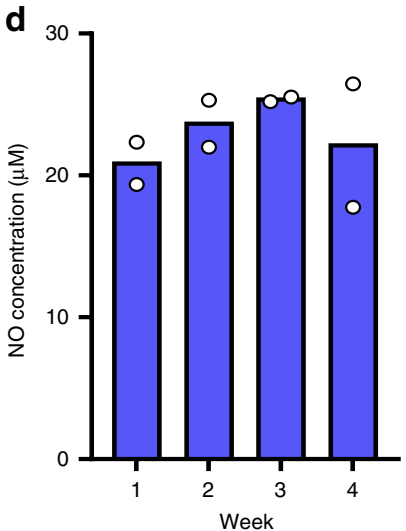

(i)

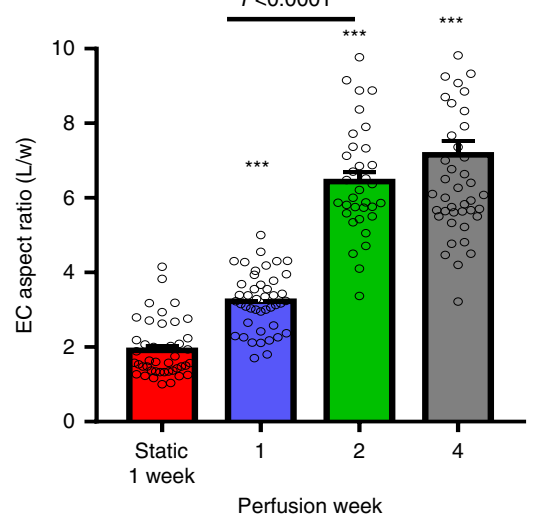

(ii)

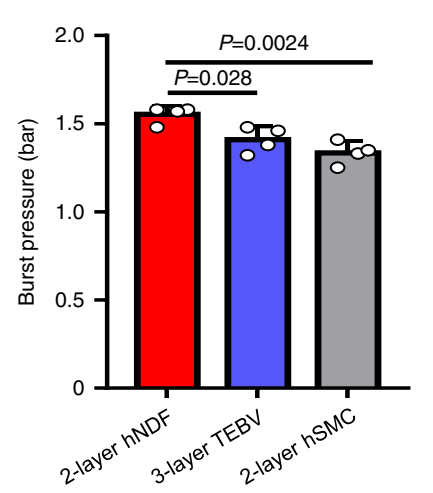

(ii)

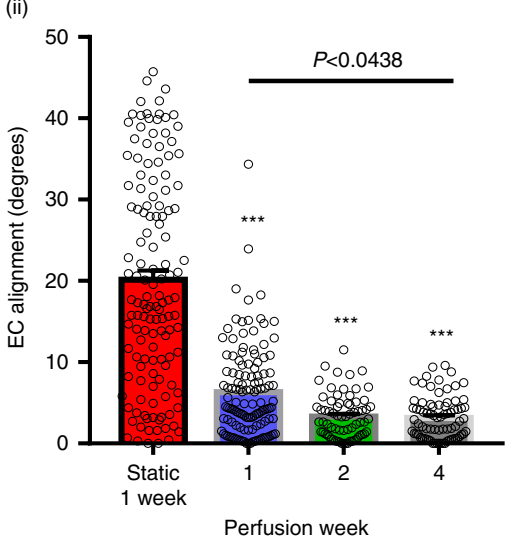

(iii)

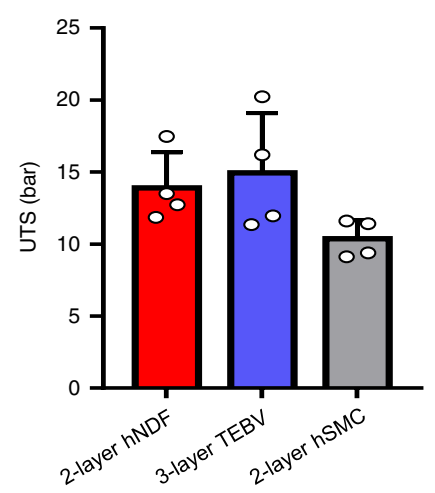

Fig. 2 TEBV functional properties and stability during 4 weeks of perfusion. Burst pressure (a) and ultimate tensile stress (UTS) (b) of endothelialized TEBVs perfused for $1-4$ weeks (mean \pm S.D., $n=3$ TEBVs, ${ }^{\star \star} P=0.00031,{ }^{\star \star \star} P<0.0001$ compared to week 0 without perfusion by one-way ANOVA). c Vasoactivity of endothelialized TEBVs perfused for 1-4 weeks (mean \pm S.D., $n=6$ TEBVs), Phe: phenylephrine, Ach: acetylcholine. $\mathbf{d}$ NO production (total nitrate and nitrite concentration in media) of endothelialized TEBVs perfused for $1-4$ weeks (mean \pm S.D., $n=2$ experiments with 4 TEBV per experiment). e The outer diameter is stable over 4 weeks perfusion, without treatment. Each point represents a value from a single TEBV at each time point. $\mathbf{f}$ ECs (endothelial cells) elongate (i) and align (ii) under perfusion (mean \pm S.E., $n=44,44,34,45$ cells for elongation and $n=134,126,70,77$ cells for alignment from 2 TEBVs, ${ }^{\star \star \star} P<0.0001$ compared to static culture by one-way ANOVA and Tukey post hoc test). $\mathbf{g}$ Vasoactivity (i), burst pressure (ii) and UTS (iii) of 2- and 3-layer TEBVs after 1-week perfusion (mean \pm S.D., $n=8$ for 2-layer-hSMC in (i) and $n=4$ for others, $P$ values determined by one-way ANOVA and Tukey post hoc test) (hNDF: human neonatal dermal fibroblasts; hSMC: human smooth muscle cells, Phe: phenylephrine; Ach: acetylcholine).

Compared to ECs in static culture TEBV, ECs on the luminal surface of TEBVs exposed to a shear stress of $0.4 \mathrm{~Pa}$ for 2 weeks perfusion were elongated and aligned with flow (Fig. 2f). ECs formed contacts with each after 1 and 2 weeks of perfusion. By 4 weeks, coverage was still very good, as noted by vWF staining, but CD31 contacts between ECs were discontinuous (Fig. S4).
To characterize the relative contractile ability of human smooth muscle cells (hSMCs) and human neonatal dermal fibroblasts (hNDFs) in TEBVs, we tested the 2-layer TEBVs with hSMCs or hNDFs and 3-layer TEBVs with both hSMCs and hNDFs. Both the 2-layer EC/hNDFs and the 3-layer (EC/hSMC/ hNDF) TEBVs exhibited good vasoactivity and mechanical strength, but the 2-layer EC/hSMCs TEBVs exhibited reduced 
vasoactivity and mechanical strength as the other two types of TEBVs (Fig. 2g). In all subsequent experiments, we only compared the difference of vasoactivity between 2-layer (EC/ hNDFs) and 3-layer TEBVs. Other studies were all completed based on 2-layer TEBVs with hNDFs.

Response of individual cell types to eLDL. LDL can be modified by oxidation $^{42}$, acetylation ${ }^{43}$, and enzymatic modification ${ }^{44}$. These modified forms of LDL activate ECs, enter macrophages by scavenger receptors, and induce the formation of foam cells. We used enzyme-modified LDL (eLDL), because eLDL is more effective than oxidized LDL in producing foam cells ${ }^{44}$, causes upregulation of ICAM-1 and E-selectin in ECs ${ }^{45}$, and readily induces foam cell formation in $\mathrm{SMCs}^{46}$ and macrophages ${ }^{44}$. The eLDL production process increased LDL particle size from $20.5 \pm$ $2.0 \mathrm{~nm}(n=2)$ to $67.0 \pm 6.5 \mathrm{~nm}(n=9)$ which is similar to the increase reported by others ${ }^{44}$. To validate that eLDL modification affected the individual cells present in our early atherosclerosis TEBV model, exposure of ECs to $100 \mu \mathrm{g} / \mathrm{ml}$ eLDL for $24 \mathrm{~h}$ induced expression of VCAM-1, ICAM-1, and E-Selectin (Fig. S5b). In contrast, treatment of ECs with $100 \mu \mathrm{g} / \mathrm{ml} \mathrm{LDL}$ did not produce an increase in ICAM-1 (Fig. S5b). eLDL concentrations as low as $10 \mu \mathrm{g} / \mathrm{ml}$ produced foam cells in macrophages after a $24 \mathrm{~h}$ exposure, whereas higher eLDL concentrations $(50 \mu \mathrm{g} / \mathrm{ml})$ were needed to produce foam cell formation in hNDFs (Fig. S5c), similar to SMCs ${ }^{46}$. Furthermore, exposure to $100 \mu \mathrm{g} / \mathrm{ml}$ eLDL for more than $48 \mathrm{~h}$ induced EC detachment but $50 \mu \mathrm{g} / \mathrm{ml}$ eLDL did not affect ECs after $96 \mathrm{~h}$ exposure. Based on these results, we used $50 \mu \mathrm{g} / \mathrm{ml}$ eLDL to treat the TEBVs.

eLDL exposure reduces TEBV vasoactivity. To model the early stages of atherosclerosis in the TEBV system and identify the contribution of a pro-inflammatory cytokine in early atherosclerosis development, TEBVs were exposed to a shear stress of $0.4 \mathrm{~Pa}$ for one week and then perfused with media containing 50 $\mu \mathrm{g} / \mathrm{ml} \mathrm{eLDL}$ with or without $50 \mathrm{U} / \mathrm{ml} \mathrm{TNFa} \mathrm{(Fig.} \mathrm{3a).} \mathrm{With} \mathrm{those}$ treatments, no changes are observed for the burst pressure and UTS of TEBVs in the different groups (Fig. 3b). Relative to untreated controls (Fig. 3c-i), vasoconstriction and vasodilation of the TEBVs was significantly reduced after $96 \mathrm{~h}$ of perfusion with eLDL (Fig. 3c-ii). Likewise, after $8 \mathrm{~h}$ of TNFa exposure, similar reductions in vasoactivity occurred (Fig. 3c-iii). The combination of both TNFa and eLDL did not have an additive effect on vasoactivity (Fig. 3c-iv). To test if these effects are reversible, after 8 days of recovery following removal of eLDL or TNFa in the perfusion media, $70 \%$ of baseline vasoactive function was recovered, a possible indication of significant recovery from eLDL specific vasoactivity changes in the early stages of atherosclerosis by correction of eLDL levels alone (Fig. 3c-ii to c-iv). The 3-layer TEBVs responded similarly to 2-layer TEBVs in control conditions and when exposed to eLDL or TNFa (Fig. S6).

Without eLDL or TNFa treatment, the TEBVs produced stable levels of NO over 12 days (Fig. 3d-i). eLDL and/or TNFa treatment led to an increase in NO production. TNFa treatment alone produced a rapid increase in NO levels, while eLDL treatment alone led to an increase in NO levels by $96 \mathrm{~h}$ treatment (Figs. 3d-i to d-iii). In the recovery period, both treatment arms demonstrated a drop in NO in the early recovery period, which was followed by slow re-establishment of baseline levels over time (Fig. 3d-ii and d-iii). No additive effect of co-treatment of eLDL and $\mathrm{TNFa}$ is observed in NO production during the early treatment or the recovery period was observed (Fig. 3d-iv).

eLDL exposure increases TEBV permeability to macromolecules. To test the permeability of the vessels with and without eLDL treatment and following recovery after removal of eLDL, $20 \mu \mathrm{g} / \mathrm{ml}$ of FITC labeled dextran $500 \mathrm{kDa}$ (Stokes-Einstein radius $=$ $15.9 \mathrm{~nm})^{47}$ or $10 \mu \mathrm{g} / \mathrm{ml}$ of FITC labeled goat IgG (Stokes-Einstein radius $=5.6 \mathrm{~nm})^{48}$ was added to the media perfused through the TEBVs, and fluorescence images were captured every $5 \mathrm{~min}$. Dextran and IgG test the sensitivity of the permeability to molecular weight and size. Dextran diffused into the vessel wall rapidly in the TEBVs without cells (Fig. S7ai), but in the perfused TEBVs with endothelium, dextran was confined to the region near the interface between the TEBV and the lumen (Fig. S7aii and S7aiii). The permeability of static culture TEBVs was lower than no-cell TEBVs but higher than perfused TEBVs, which demonstrated that perfusion increases the EC junction integrity (Fig. 4b). The permeability of TEBV s to dextran with and without the endothelial layer is $5.9 \pm$ $1.4 \times 10^{-7} \mathrm{~cm} / \mathrm{s}$ and $2.8 \pm 0.1 \times 10^{-6} \mathrm{~cm} / \mathrm{s}$ at $10 \mathrm{~min}$ and $6.3 \pm 2.3 \times$ $10^{-7} \mathrm{~cm} / \mathrm{s}$ and $3.3 \pm 0.4 \times 10^{-6} \mathrm{~cm} / \mathrm{s}$ at $20 \mathrm{~min}$ (Fig. $4 \mathrm{a}$ ). The permeability of TEBVs significantly dropped with the endothelial layer present, which served as additional evidence for the presence of functional endothelial layer. After eLDL exposure for $96 \mathrm{~h}$, the permeability of endothelial TEBVs increased to $2.3 \pm 1.7 \times 10^{-6} \mathrm{~cm} /$ $\mathrm{s}$ at $10 \mathrm{~min}$ and to $3.0 \pm 1.8 \times 10^{-6} \mathrm{~cm} / \mathrm{s}$ at $20 \mathrm{~min}$, which is about 5 times higher compared to the control group (Fig. 4a). After 8 days of recovery post eLDL exposure, the permeability of TEBVs was still $2.1 \pm 1.3 \times 10^{-6}$ at $10 \mathrm{~min}$ and $1.7 \pm 1.2 \times 10^{-6}$ at $20 \mathrm{~min}$, which revealed the barrier function of TEBVs did not recover in 8 days (Fig. 4a). The IgG permeability of TEBVs was similar to dextran $500 \mathrm{kDa}$ in all the groups. Thus, the barrier function of TEBVs was stable to different large molecules (radius 5-15 nm) and was impaired by eLDL.

Inflammation in TEBVs similar to early stages of atherosclerosis inflammation. Early inflammatory changes are a crucial factor in atherosclerosis development ${ }^{7,8}$. In the absence of eLDL or TNFa, VCAM-1, ICAM-1, and E-selectin expression were absent or present at very low levels (Fig. 5a). Activation of endothelial cells after eLDL and TNFa addition to the perfusion media was characterized by increased expression of VCAM-1, ICAM-1, and E-selectin (Fig. 5a) at flow rates of $0.125 \mathrm{ml} / \mathrm{min}(0.1 \mathrm{~Pa})$ per TEBV and $0.5 \mathrm{ml} / \mathrm{min}(0.4 \mathrm{~Pa})$ per TEBV. Treatment with eLDL led to slight increases in the expression of ICAM-1 and E-selectin at both flow rates, while TNFa treatment led to upregulation of VCAM-1 and E-selectin at $0.4 \mathrm{~Pa}$ (Fig. 5b). When the perfusion media contained $50 \mu \mathrm{g} / \mathrm{ml} \mathrm{eLDL}$ for $96 \mathrm{~h}$ and $50 \mathrm{U} / \mathrm{ml} \mathrm{TNFa}$ during the last $8 \mathrm{~h}$ of eLDL perfusion, all three adhesion molecules were elevated relative to controls. After 8 days of recovery $(0.1 \mathrm{~Pa})$, the activation of endothelial cells subsided in all the groups (Fig. 5a, b), further suggesting early stages of atherosclerosis may be partly reversible. Furthermore, eLDL and TNFa treatment led to increased expression of TNF $\alpha$ and IL-1 $\beta$ in the TEBVs (Fig.5c) with a synergistic response to the combination of eLDL and TNFa. Expression of TNF $\alpha$ and IL- $1 \beta$ declined after 8 days of recovery but remained 2-3 times higher than controls.

Next, we examined the expression level of ECM genes Col I, Col III, and Col IV in the TEBVs. Col I and Col IV expression did not change following 96 exposure to $50 \mu \mathrm{g} / \mathrm{ml}$ eLDL or $8 \mathrm{~h} \mathrm{TNFa}$ treatment (Fig. 5d). After removal of eLDL from the perfusion media for 8 days, Col I and Col IV gene expression increased.

Monocytes accumulation in TEBVs after eLDL exposure. Monocyte/macrophages play an important role in the early stages of atherosclerosis ${ }^{49}$. After establishing that the individual cell types responded to eLDL, we examined the effect of different eLDL concentrations and exposure periods to cause substantial increases in monocyte accumulation. Adding 50 or $100 \mu \mathrm{g} / \mathrm{ml} \mathrm{eLDL}$ to the perfusion media for $48 \mathrm{~h}$ and adding 
a
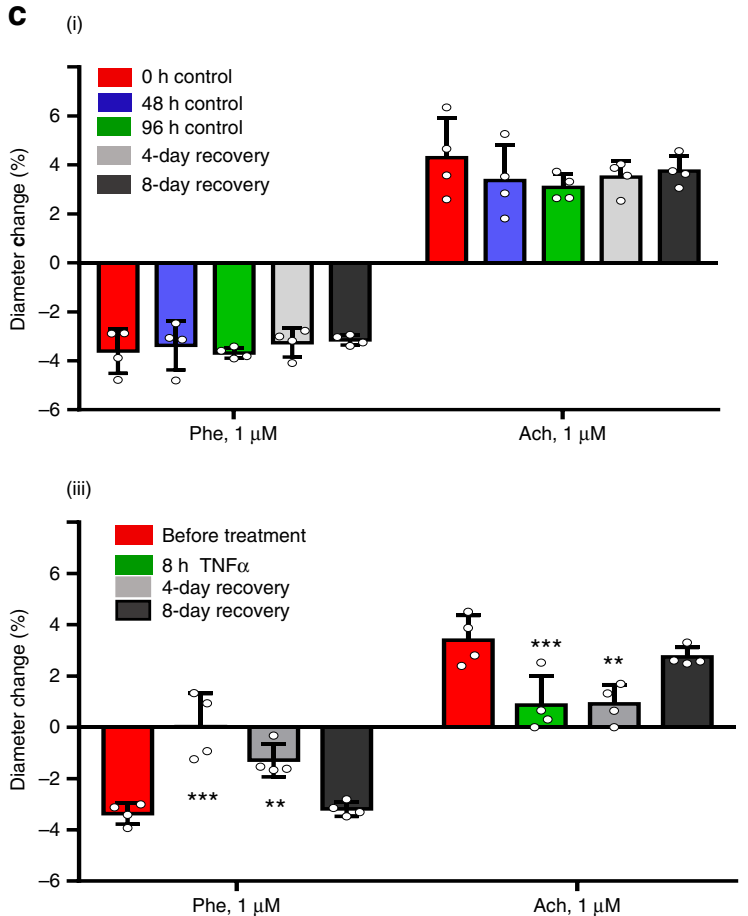

d
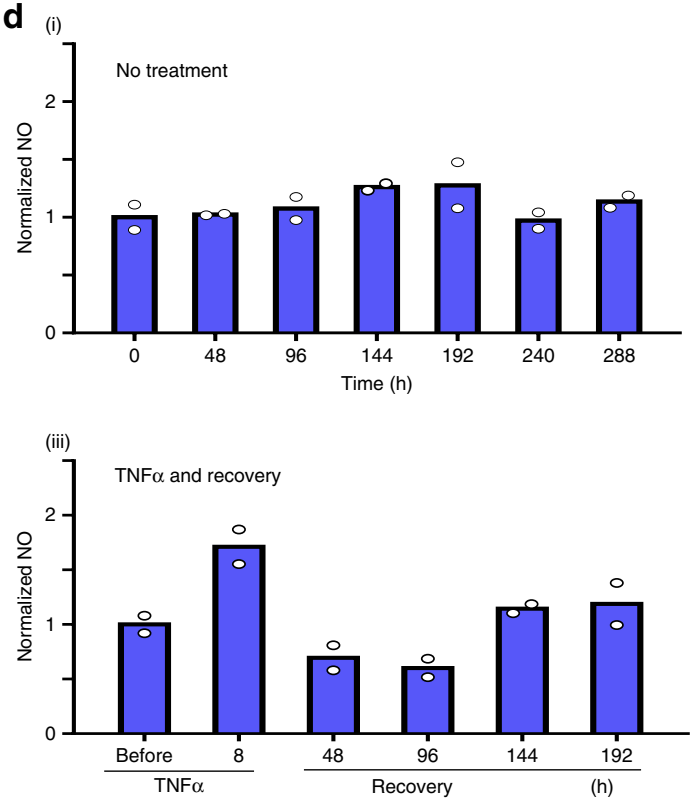

$1 \times 10^{6}$ U937 monocytes/ml during the last $24 \mathrm{~h}$ of eLDL exposure (Fig. 6a) produced a modest increase in monocyte accumulation, which increased greatly if $50 \mathrm{U} / \mathrm{ml} \mathrm{TNFa}$ is added during the last $8 \mathrm{~h}$ (Fig. $6 \mathrm{~b}$ ).

We next investigated monocyte accumulation in TEBVs following longer eLDL and monocyte exposure periods. After
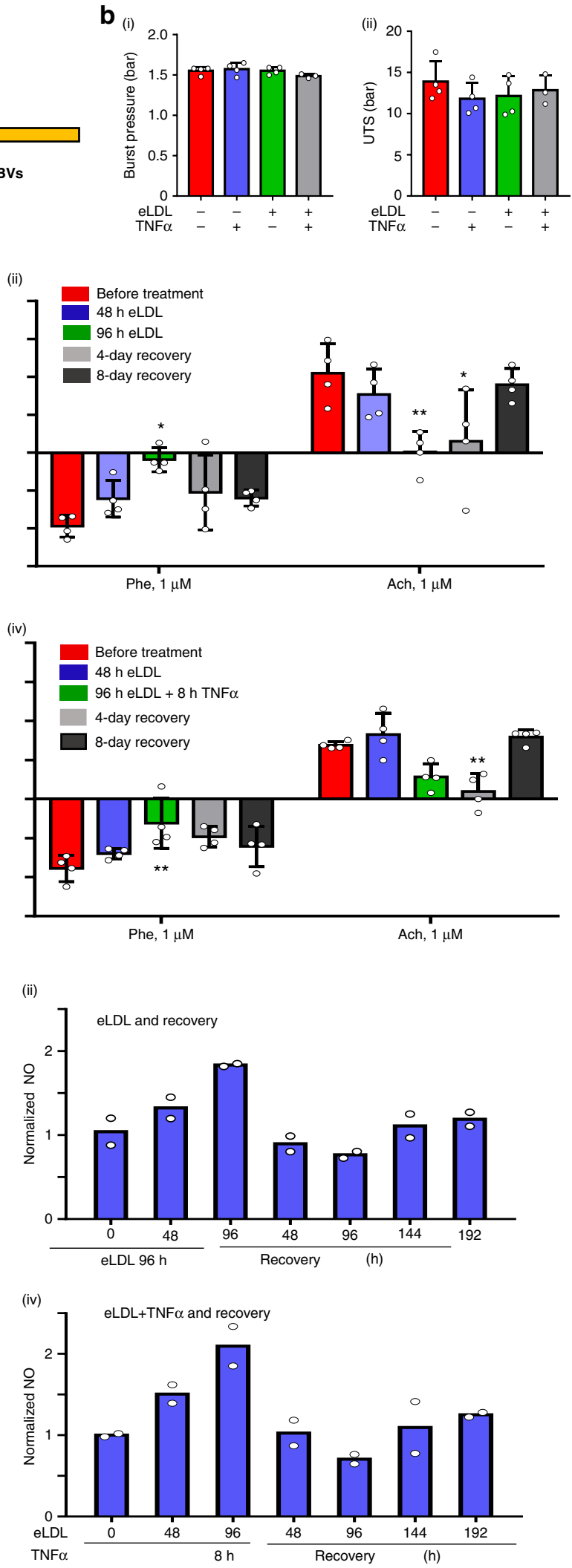

one week of maturation, TEBVs are treated with $50 \mu \mathrm{g} / \mathrm{ml}$ eLDL for times up to $96 \mathrm{~h}$ with or without $100 \mathrm{U} / \mathrm{ml} \mathrm{TNFa}$ for the last $8 \mathrm{~h}$ of perfusion with eLDL (Fig. 6c). After $72 \mathrm{~h}$ of perfusion at $0.125 \mathrm{ml} / \mathrm{min}$ per TEBVs $(0.1 \mathrm{~Pa})$, labeled monocytes accumulated on the luminal endothelial cells. Few monocytes adhered in the absence of eLDL or TNFa (Fig. 6d, e). The number of 
Fig. 3 Dysfunction and recovery of TEBVs by eLDL and/or TNF $\boldsymbol{\alpha}$ exposure. a Timeline of TEBV treatment. $\mathbf{b}$ Burst pressure (i) and UTS (ii) of TEBVs after $96 \mathrm{~h}$ eLDL $\pm 8 \mathrm{~h}$ TNF $\alpha$ exposure (mean \pm S.D., $n=3$ TEBVs for $+/+$ and $n=4$ TEBVs for others). c (i) Vasoactivity for perfusion without treatment. (ii) Vasoactivity for perfusion with $50 \mu \mathrm{g} / \mathrm{ml}$ eLDL followed by 8 days of recovery without eLDL in perfusion media (mean \pm S.D., $n=4$ TEBVs, Phe: ${ }^{\star} P=$ 0.0335 ; Ach: ${ }^{\star} P=0.028053 ;{ }^{\star} P=0.006529$ compared to before treatment by two-way ANOVA and Tukey post hoc test). (iii) Vasoactivity for perfusion for $8 \mathrm{~h}$ with $50 \mathrm{U} / \mathrm{ml}$ TNF $\alpha$ exposure followed by 8 days of recovery without TNF $\alpha$ (mean \pm S.D., $n=4$ TEBVs, Phe: ${ }^{\star \star} P=0.00246,{ }^{\star \star \star} P<0.0001$; Ach: ${ }^{\star \star} P=0.0049,{ }^{\star \star} P=0.0041$; Ach ${ }^{\star \star} P=0.0049$, compared to before treatment by two-way ANOVA and Tukey post hoc test). (iv) Vasoactivity for perfusion with $50 \mu \mathrm{g} / \mathrm{ml}$ eLDL for $96 \mathrm{~h}$ and $50 \mathrm{U} / \mathrm{ml} \mathrm{TNF} \alpha$ for $8 \mathrm{~h}$ and 8 days of recovery (mean \pm S.D., $n=4$ TEBVs, Phe: ${ }^{* \star} P=0.0081 ;$ Ach ${ }^{* \star} P=0.0065$ compared to before treatment by two-way ANOVA and Tukey post hoc test). Phe: phenylephrine, Ach: acetylcholine (c). d Normalized NO production (total nitrate and nitrite concentration in media) of TEBVs with no treatment (i), $96 \mathrm{~h}$ of eLDL (ii), $8 \mathrm{~h}$ of TNF $\alpha$ (iii), $96 \mathrm{~h}$ eLDL $+8 \mathrm{~h}$ TNF $\alpha$ (iv) exposure and 8 days of recovery $(n=2$ from 8 TEBVs).

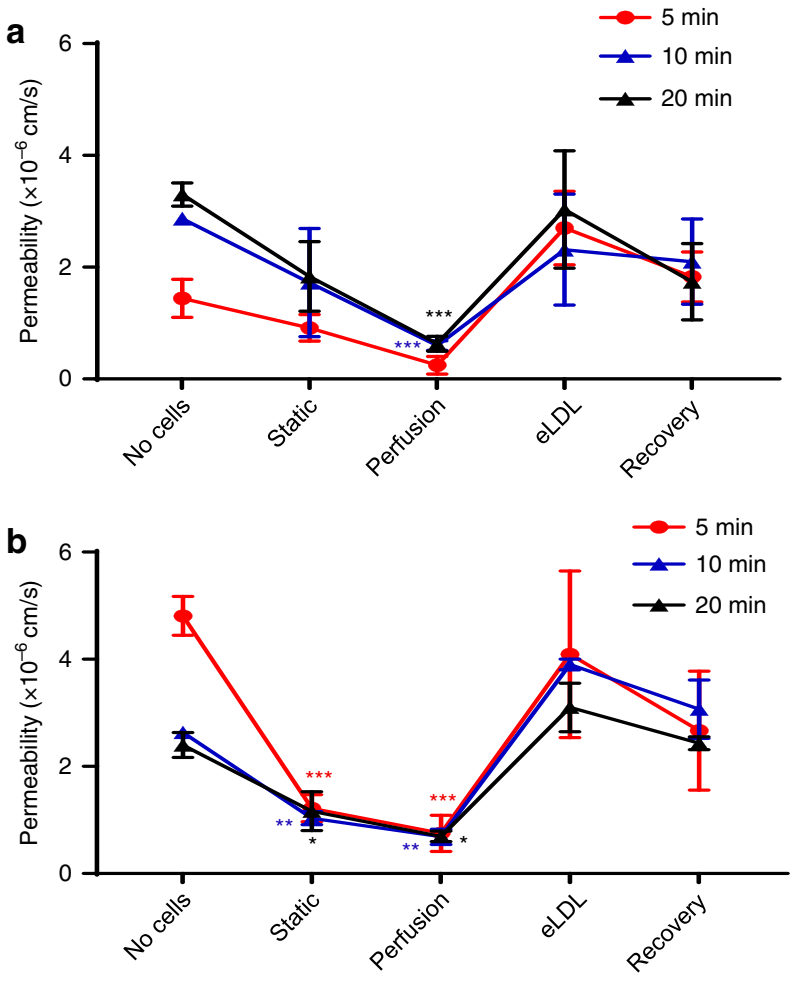

Fig. 4 Perfusion reduces TEBV EC permeability. Permeability of TEBVs to $20 \mu \mathrm{g} / \mathrm{ml}$ of FITC-dextran (500 kDa) (a) and to $10 \mu \mathrm{g} / \mathrm{ml}$ of FITC-lgG (b). The groups are collagen tubing without cells and without perfusion (No cells), TEBVs with cells under static culture of 1 week (Static), TEBVs with cells for 1-week perfusion perfused at $0.5 \mathrm{ml} / \mathrm{min}$ per TEBV (0.4 Pa) (perfusion), TEBVs under 1-week perfusion followed by $96 \mathrm{~h}$ perfusion with media containing $50 \mu \mathrm{g} / \mathrm{ml}$ eLDL (eLDL), TEBVs following $96 \mathrm{~h}$ exposure to $50 \mu \mathrm{g} / \mathrm{ml}$ eLDL followed by 8 days without eLDL (Recovery) (mean \pm S.D., $n=3$ TEBVs, (a) perfusion: ${ }^{\star \star \star} P=0.00066(10 \mathrm{~min}),{ }^{\star \star \star} P=0.000105$ (20 min), (b) static ${ }^{\star \star \star} P=<0.0001(5 \mathrm{~min}),{ }^{\star \star} P=0.00785(10 \mathrm{~min}),{ }^{\star} P=$ 0.0358 (20 min), Perfusion: ${ }^{\star \star \star} P<0.0001$ (5 min), ${ }^{\star \star} P=0.00161$ (10 min), ${ }^{\star} P=0.0488(20 \mathrm{~min})$, compared to no-cell group by a two-way ANOVA and Tukey post hoc test).

monocytes adhered on eLDL treated TEBVs was $50-100 \%$ higher than for control vessels (Fig. 6f). Co-treatment of TNFa and eLDL substantially enhanced the accumulation of monocytes up to 3-4 times the control levels (Fig. 6f). At a higher flow rate of $0.5 \mathrm{ml} / \mathrm{min}$ per TEBV $(0.4 \mathrm{~Pa})$ monocyte adhesion was reduced in control TEBVs but had little effect on TEBVs exposed to either eLDL or TNFa. To the eLDL + /TNF + treatment, the accumulation of monocytes under high shear stress declined about $25 \%$ compared to the low shear stress case, but was still higher than the groups with eLDL or TNFa treatment.
Migration of monocytes into the vessel wall was also observed (Fig. 6g). After $72 \mathrm{~h}$ prefusion, the migration distance of monocytes is about $30-50 \mu \mathrm{m}$ within the vessel wall (Fig. 5e), a process similar to what is seen in vivo ${ }^{1}$.

Next, we perfused whole blood with $25-30 \%$ CPD through the TEBV lumen (Fig. S8). Although the blood contained CPD to prevent clotting, perfusion of whole blood for more than $40 \mathrm{~h}$ did lead to obstruction of the TEBVs and the flow rate declined significantly. We modified the protocol to perfuse the TEBVs for 7 days with the perfusion media as before (Fig. 6h). Next, the media was replaced with whole blood with or without $50 \mu \mathrm{g} / \mathrm{ml}$ eLDL which was perfused at $0.5 \mathrm{ml} / \mathrm{min}(0.4 \mathrm{~Pa})$ for $24 \mathrm{~h}$, after which $10^{6} / \mathrm{ml}$ cell tracker labeled monocytes were added and the blood perfused for another $40 \mathrm{~h}$ at $0.125 \mathrm{ml} / \mathrm{min}(0.1 \mathrm{~Pa})$. A shear stress of $0.1 \mathrm{~Pa}$ approximates the mean value at vessel branches where atherosclerosis originates ${ }^{50}$. A control without blood was performed simultaneously.

Compared to perfusion with culture media, perfusion with whole blood increased monocyte accumulation in the TEBVs $\sim 3.4 \mathrm{X}$ without eLDL treatment (Fig. 6i). When TEBVs were exposed to whole blood containing eLDL, monocyte adhesion increased another $50 \%$.

Foam cell formation in TEBVs. To characterize foam cell formation, TEBVs treated as in Fig. 6c were stained with Oil Red$\mathrm{O}$. Oil Red $\mathrm{O}+$ monocytes were adherent to the vessel lumen (Fig. 6j, k) as well as within the TEBVs. The hNDFs in TEBVs accumulated eLDL after $96 \mathrm{~h}$ exposure and many Oil Red O + regions are observed in the cells (Fig. 61 and Fig. S9). Oil Red $\mathrm{O}+$ regions in the endothelial layer were rare after $96 \mathrm{~h}$ eLDL exposure, which revealed that ECs deliver but do not accumulate eLDL (Fig. S9iii). This result is consistent with in vivo studies with mice ${ }^{51}$.

However, U937 monocytes did not express CD80, an important marker of $\mathrm{M} 1$ phase macrophages ${ }^{52}$, consistent with other reports ${ }^{53}$. Next, we examined primary monocyte polarization into macrophages in both $2 \mathrm{D}$ and the TEBV system. In $2 \mathrm{D}$, primary monocytes were tested with or without pretreatment of Granulocyte-Macrophage Colony Stimulating Factor (GM-CSF). GM-CSF promotes monocyte polarization to pro-inflammatory macrophages and dendritic cells ${ }^{54}$. Without GM-CSF pretreatment, levels of CD80 were low (CD80 expression was $15-22 \%$ after eLDL and/or a treatment). Further, eLDL and/or TNFa treatment did not increase the number of CD80 + cells. Thus, we pretreated the primary monocytes with $20 \mathrm{ng} / \mathrm{ml}$ GM-CSF for three days, which increased the baseline of CD80 expression from $<10 \%$ to $>40 \%$ and increased the primary monocytes survival ratio in vitro. GM-CSF treated monocytes were then exposed to 50 $\mu \mathrm{g} / \mathrm{ml}$ eLDL and/or $50 \mathrm{U} / \mathrm{ml} \mathrm{TNFa}$ for $72 \mathrm{~h}$. eLDL and TNFa treatments increased expression of CD206, a common marker for polarization into macrophages ${ }^{52}$. TNFa alone, eLDL alone, 
a
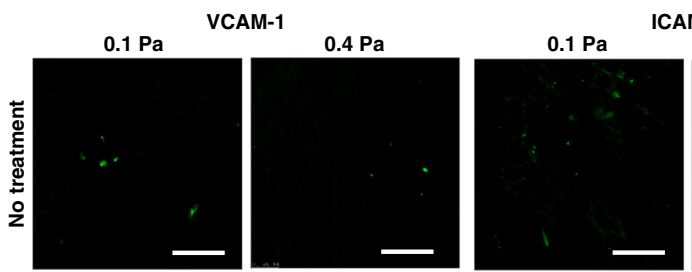

CAM-1

$0.4 \mathrm{~Pa}$
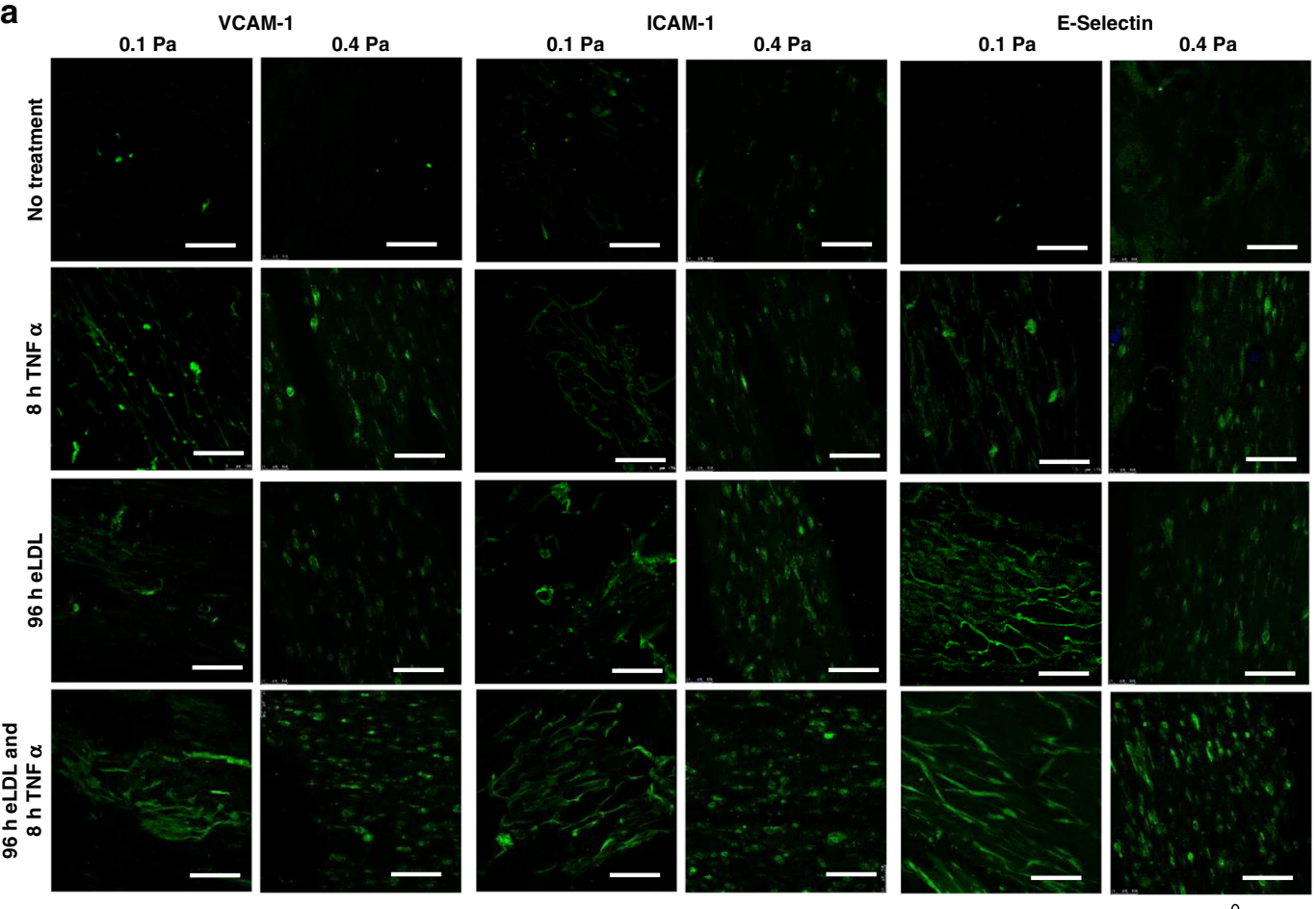

b

$0.1 \mathrm{~Pa} \quad 0.4 \mathrm{~Pa} \quad$ Recovery
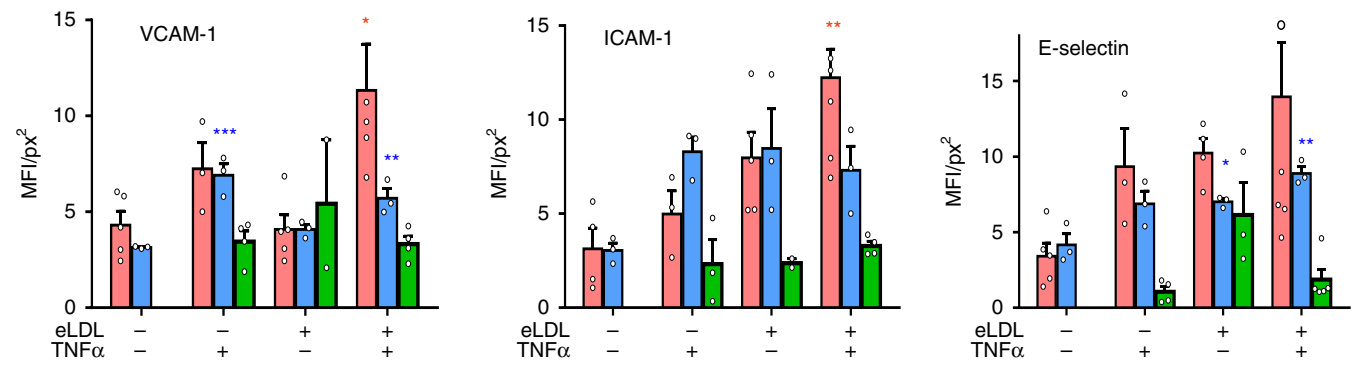

C
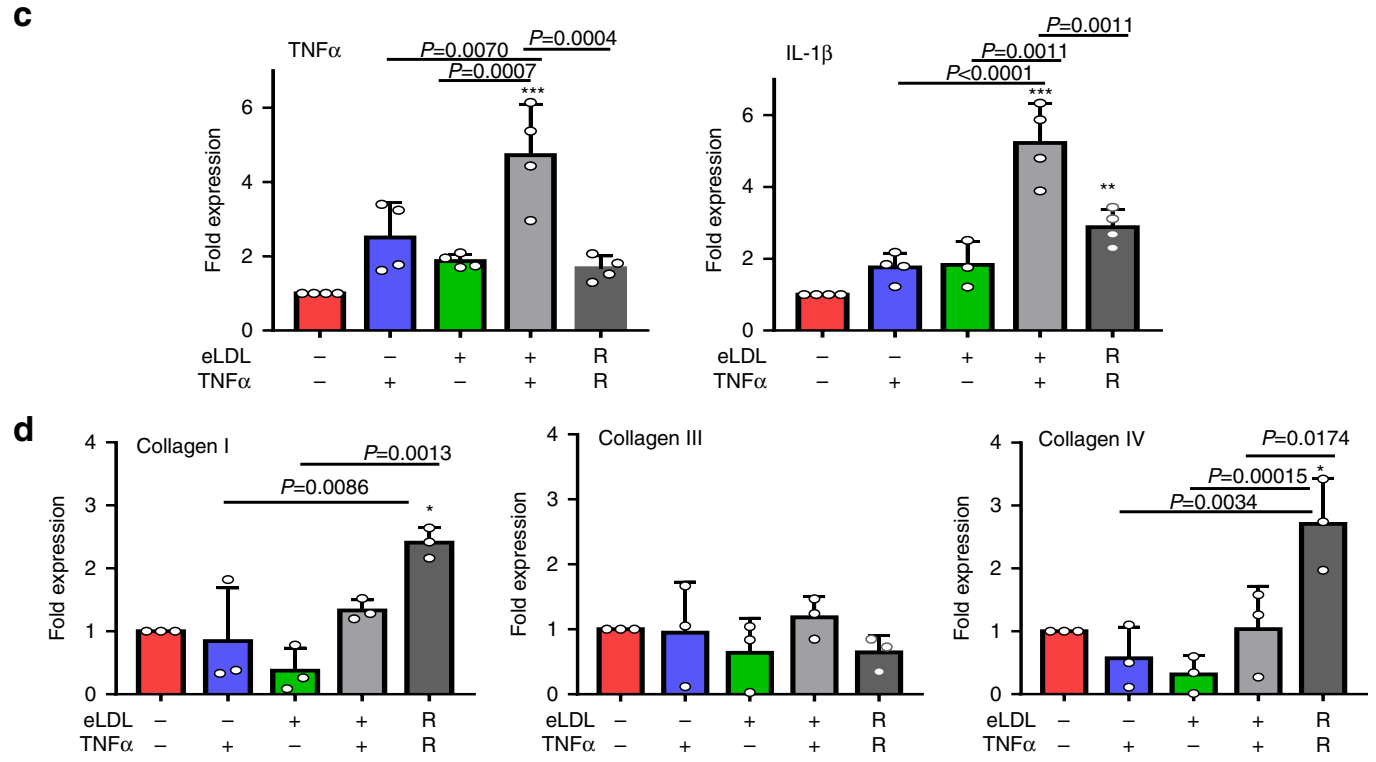

and both combined had differential effects on CD80 expression (Fig. 7a, b). Expression of CD36, an important scavenger receptor is greatly increased in the treatment groups (Fig. 7a, b). This receptor present on monocytes and macrophages has an important function in lipid uptake and foam cell formation ${ }^{55,56}$.
Next, TEBVs were perfused with media, TNFa, or eLDL with or without TNFa as shown in Fig. 6c. Following $72 \mathrm{~h}$ perfusion at $0.125 \mathrm{ml} / \mathrm{min}$ per TEBV $(0.1 \mathrm{~Pa})$ with GM-CSF-treated primary monocytes labeled with cell tracker red, monocytes that accumulated in the TEBVs were characterized through 
Fig. 5 Inflammatory response of TEBVs following exposure to eLDL or TNF $\alpha$. a Fluorescence images of VCAM-1, ICAM-1 or E-selectin expression on TEBV ECs after flow of $0.125 \mathrm{ml} / \mathrm{min}$ per vessel $(0.1 \mathrm{~Pa})$ and $0.5 \mathrm{ml} / \mathrm{min}$ per vessel $(0.4 \mathrm{~Pa})$ for 8 days followed by exposure to media alone for $96 \mathrm{~h}$, media with $50 \mu \mathrm{g} / \mathrm{ml}$ eLDL for $96 \mathrm{~h}$, media alone for $96 \mathrm{~h}$ followed by media and $50 \mathrm{U} / \mathrm{ml} \mathrm{TNF} \alpha$ for the last $8 \mathrm{~h}$, or media with $50 \mu \mathrm{g} / \mathrm{ml}$ eLDL for $96 \mathrm{~h}$ and $50 \mathrm{U} /$ $\mathrm{ml} \mathrm{TNF} \alpha$ for the last $8 \mathrm{~h}$ (scale bar: $200 \mu \mathrm{m}$ ). $\mathbf{b}$ Quantification of mean fluorescence intensity (MFI) of the images in $5 \mathrm{a}$ and following the recovery for 8 day at $0.5 \mathrm{ml} / \mathrm{min}$ (mean $\pm \mathrm{S}$.E., $n=5,3,3,3,4,5,3,2,5,3,4$ TEBV s for VCAM-1 accordingly, $n=4,3,3,3,3,5,3,2,7,3,4$ TEBVs for ICAM-1 accordingly, $n=$ 5,3,3,3,4,4,3,3,7,3,5 TEBVs for E-Selectin accordingly, VCAM-1 0.1 Pa ${ }^{\star} P=0.0195,0.4 \mathrm{~Pa}, 0.4 \mathrm{~Pa}{ }^{\star \star} P=0.0094,{ }^{\star \star \star} P=0.0008 ;$ ICAM-1 0.1 Pa ${ }^{\star \star} P=$ $0.0021,0.4 \mathrm{~Pa}$; E-selectin $0.4 \mathrm{~Pa}{ }^{\star} P=0.0448,{ }^{\star} P=0.0027$ relative to the respective control by one-way ANOVA and Tukey post hoc test at each shear stress). c RT-PCR of TNF $\alpha$ and IL- $1 \beta$ (mean \pm S.D., $n=3$ TEBVs for $+/-$ in IL- $1 \beta n=4$ TEBVs for others, ${ }^{\star \star} P=0.0069,{ }^{\star \star \star} P<0.0001$, compared to control by two-way ANOVA) and (d) RT-PCR collagen I, III, and IV expression (mean \pm S.D., $n=3$ TEBVs, Col I: ${ }^{\star} P=0.0169$, Col IV: ${ }^{\star} P=0.0152$ compared to control by one-way ANOVA and Tukey post hoc test) after treatment with eLDL for $96 \mathrm{~h}$ and/or TNF $\alpha$ for $8 \mathrm{~h}$, and 8 days of recovery (R) after treatment with $L D L$ and/or TNF $\alpha$ at a flow rate of $0.5 \mathrm{ml} / \mathrm{min}$.

CD80 staining. All CD80 positive cells (green in Fig. 7c) are positive for cell tracker red. CD80 expression of macrophages accumulating in the TEBVs was similar to experiments with isolated monocytes (Fig. 7b) in which eLDL leads to significant increase in the CD80 expression, with a smaller increase for TNFa only treatment (Fig. 7c, d). An additional additive effect in CD80 expression is seen with both eLDL and TNFa co-treatment.

Inhibition of effect of eLDL on TEBV function. Lovastatin is a widely used hydroxymethylglutaryl coenzyme A (HMG-CoA) reductase inhibitor, that decreases mevalonate production, an important part of cholesterol synthesis ${ }^{57}$. Treatment of the perfusion media with Lovastatin together with eLDL blocked the reduction in vasoactivity induced by eLDL (Fig. S8ai) and eLDLinduced NO production (Fig. S8aii). Addition of Lovastatin inhibits the uptake of eLDL in hNDFs and foam cell formation (Fig. S10). Lovastatin treatment blocked the effect of TNFa exposure on TEBV vasoactivity, with almost no change in NO production (Fig. 8bi, ii). Lovastatin treatment significantly decreases monocyte accumulation in TEBVs treated with eLDL, with no effect seen for TNFa treatment (Fig. 8c). Reduced monocyte adhesion and accumulation may be related to the marked decrease in ICAM-1 and E-selectin expression when eLDL exposed vessels are treated with Lovastatin (Fig. 8d). Furthermore, Lovastatin blocked CD80 expression induced by both eLDL and TNFa (Fig. 8e), and CD36 expression induced by eLDL, or TNFa (Fig. 8f).

Next, we examined whether blocking the $\mathrm{P}_{2} \mathrm{Y}_{11}$ receptor with NF157 altered vasoactivity ${ }^{58}$, EC inflammation and monocyte accumulation. The $\mathrm{P}_{2} \mathrm{Y}_{11}$ receptor is a G-protein coupled receptor for ATP and is present in humans but not mice or rats $^{58}$. Blockade with NF157 inhibited inflammation on endothelial cells induced by oxidized $\mathrm{LDL}^{59}$. In control experiments, exposure to $50 \mu \mathrm{g} / \mathrm{ml}$ eLDL inhibited vasoconstriction after $96 \mathrm{~h}$ exposure and inhibited vasodilation by $48 \mathrm{~h}$ exposure and TEBV vasoactivity recovered after 8 days (Fig. 9a). Addition of $25 \mu \mathrm{M}$ NF157 with $50 \mu \mathrm{g} / \mathrm{ml}$ eLDL, caused a delayed inhibition of vasoconstriction and vasodilation with full recovery by 6 days after removal of eLDL (Fig. 9b). When monocytes were added during the last $72 \mathrm{~h}$ of perfusion at $0.5 \mathrm{ml} / \mathrm{min}(0.4 \mathrm{~Pa})$, addition of $25 \mu \mathrm{M}$ NF 157 caused a significant reduction in monocyte accumulation (Fig. 9c) and slightly reduced expression of VCAM1, ICAM-1 and E-selection (Fig. 9d).

\section{Discussion}

In this work, we established a rapid and reproducible method to generate tissue-engineered blood vessels to model early stages of atherosclerosis, including eLDL-induced atherogenesis. Plastic compression of collagen TEBVs provides burst pressure and ultimate tensile strengths similar to veins and TEBVs generated with synthetic materials ${ }^{4}$. After endothelization and perfusion, the TEBVs exhibited key vessel functions, including vasoactivity, NO production, and low permeability. The permeability values measured in this study are similar to those obtained with human umbilical vein endothelial cells $21,60,61$ and human dermal microvascular endothelial cells ${ }^{25}$ forming the luminal surface of vascular networks in hydrogel scaffolds exposed to physiological shear stresses for 4-7 days. The physiologically relevant microenvironment generated in our system includes physiologically relevant shear stress and flow conditions, an important element in accurately modeling vascular health and disease states. This is especially true given the significant role that shear stress plays in endothelial response to injury and disease progression.

The TEBV system was then used to model early stages of atherosclerosis, with controlled introduction of different elements characteristic of the disease, including increased concentrations of eLDL, leading to cellular uptake and foam cell formation, monocyte activation and accumulation, an inflammatory environment leading to activation of ECs and monocytes, and early effects on vasoactivity ${ }^{1,2,6}$. After perfusion of TEBVs for 96 with $50 \mu \mathrm{g} / \mathrm{ml}$ eLDL, the ECs exhibited properties similar to those reported previously, including EC expression of E-selectin and ICAM-1 $1^{45,62}$ which then led to fibroblast and macrophage foam cells.

Since we used a straight segment of TEBV, flow rates used produce shear stresses that favor promotion of atherosclerosis ${ }^{63}$. Nonetheless, without eLDL or TNFa in the media, leukocyte adhesion molecule expression was very low with minimal monocyte adhesion. While a $48 \mathrm{~h}$ perfusion with $50 \mu \mathrm{g} / \mathrm{ml} \mathrm{eLDL}$ caused a modest increase in monocyte accumulation, $96 \mathrm{~h}$ treatment with $50 \mu \mathrm{g} / \mathrm{ml}$ eLDL leads to significant accumulation of monocytes in TEBVs, reduced vasoactivity, elevated NO levels, and elevated endothelial permeability. These changes are associated with increased gene expression of IL-1 $\beta$ and TNFa in the TEBVs. The flow rates of $0.1 \mathrm{~Pa}$ and $0.4 \mathrm{~Pa}$ in vessels only had effect on the monocytes accumulation in the control group but have less effect to eLDL/TNFa treatment groups. This result may demonstrate that for healthy people, the exercise to increase blood flow rate could reduce the monocytes adherence in vivo, but with disease, monocytes can still adhere to the endothelium and accumulate. Interestingly, foam cell formation with eLDL preceded macrophage polarization, at least as judged by CD80 expression.

Addition of eLDL and TNFa together produced synergistic increases in adhesion molecule levels and gene expression of IL$1 \beta$ and $\mathrm{TNF} \alpha$, as well as monocyte accumulation. A recent largescale clinical trial demonstrated the efficacy of IL-1 $\beta$ blockade in decreasing cardiovascular events ${ }^{12}$. Furthermore, whole blood increases monocyte adherence compared to media, which resulted from the complex composition of blood. This phenomenon may explain the delayed response of ECM gene expression levels to eLDL and TNFa in Fig. 5c. 
a

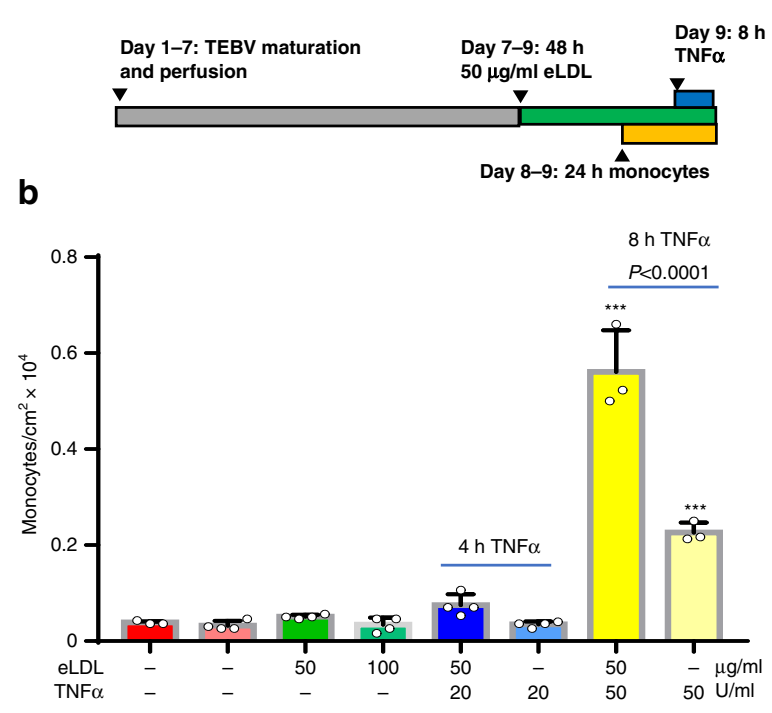

C
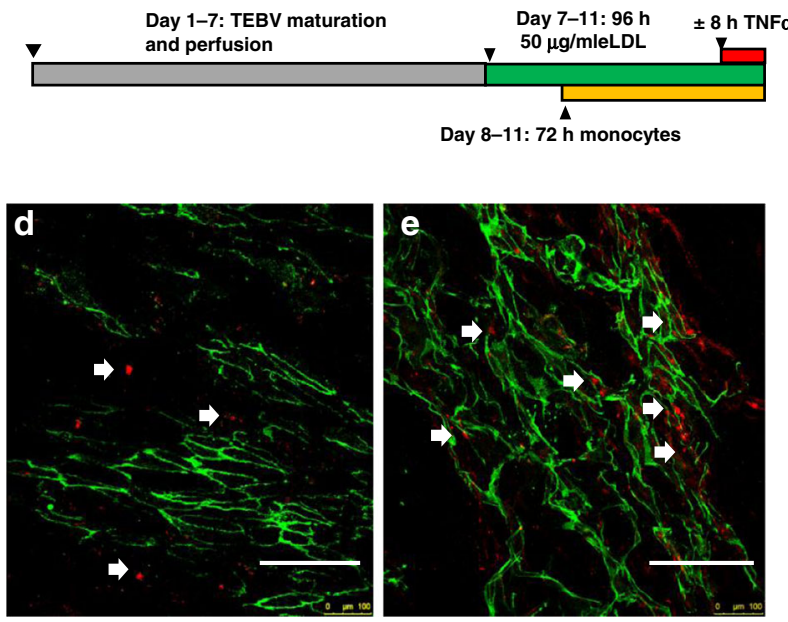

$\mathbf{f}$

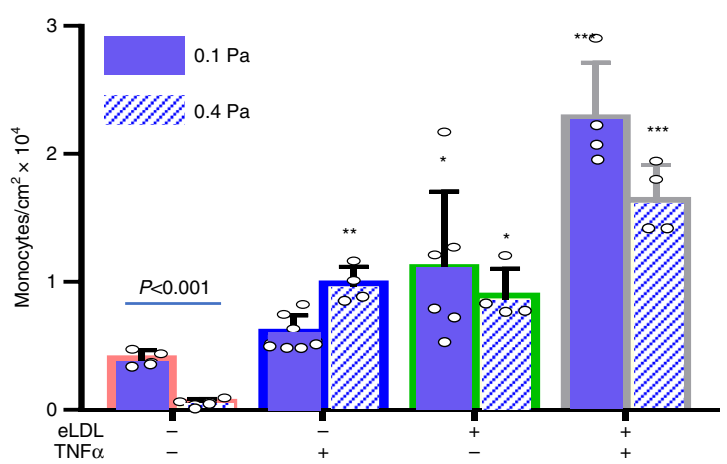

g

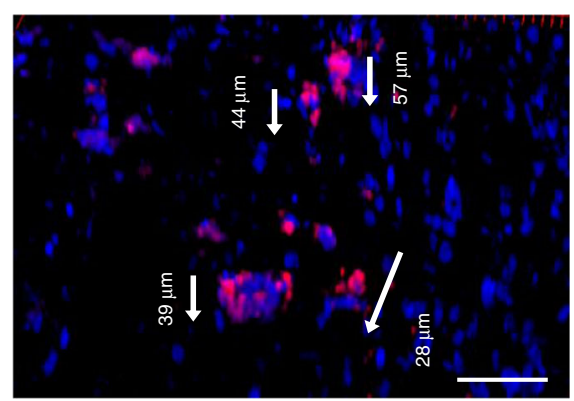

h
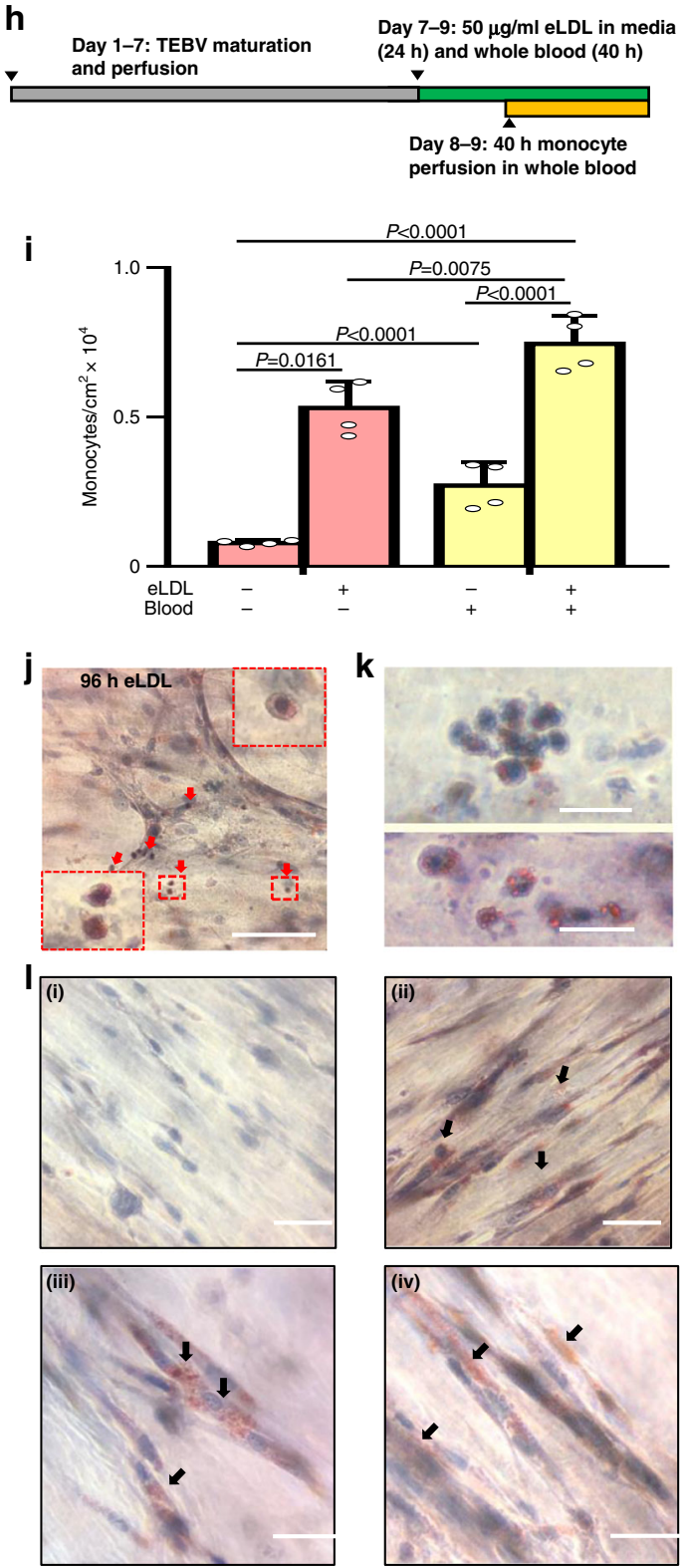

The TEBV system we developed offers several advantages. The compact chip, with replicates in a single device, enables multiple conditions to be examined using several chips run separately in an incubator. We designed the TEBVs with this dimension (OD: $1 \mathrm{~mm}$, ID: $0.6 \mathrm{~mm}$ ) because it is at the same level of a small artery and larger arteriole ( $\mathrm{mm}$ level) and the perfusion chips with 4 TEBVs are small enough to be imaged clearly under stereomicroscope. Further, the human TEBV microphysiological system can isolate specific effects that are difficult to assess in vivo, such separate a direct effect of statins on the vessel wall from their cholesterol-lowering effect. By keeping the diameter small, media volumes and flow rates can be maintained at small values to replicate physiological shear stresses ( $\mathrm{ml} / \mathrm{min}$ or less). Small volumes are ideal to measure any metabolites, secreted 
Fig. 6 Accumulation and differentiation of monocytes in the TEBV atherosclerosis disease model. a Experimental design of $48 \mathrm{~h}$ TEBV treatment with eLDL. $10^{6}$ cell/ $\mathrm{ml}$ of cell-tracker-red labeled $U 937$ monocytes were added to culture media without and with $50 \mathrm{\mu g} / \mathrm{ml}$ eLDL and monocyte accumulation in TEBVs measured after $48 \mathrm{~h} .50 \mathrm{U} / \mathrm{ml} \mathrm{TNF} \alpha$ added during last $8 \mathrm{~h}$ in some experiments with or without eLDL. b Quantification of monocytes/cm ${ }^{2}$ from en face sections of TEBVs $\left(n=3\right.$ TEBVs for $-/-, 50 / 50,-/ 50$ and $n=4$ TEBVs for others, Mean \pm S.D.) ${ }^{\star \star \star} P<0.0001$ relative to control by one-way ANOVA and Tukey post hoc test. c Experimental design of $48 \mathrm{~h} \mathrm{TEBV}$ treatment with eLDL. En face views of monocyte (cell tracker-red) accumulation (arrow) in TEBVs without (d) and with $50 \mu \mathrm{g} / \mathrm{ml}$ eLDL (e) in perfusion media (scale bar $200 \mu \mathrm{m}$ ). CD31 positive endothelium shown in green.

f Quantification of monocyte accumulation in TEBVs for different treatment conditions at flow rates of $0.125 \mathrm{ml} / \mathrm{min} \mathrm{per} \mathrm{vessel}(0.1 \mathrm{~Pa})$ and $0.5 \mathrm{ml} / \mathrm{min}$ (0.4 Pa) per vessel (mean \pm S.D., $n=4,7,6,4$ TEBVs for $0.1 \mathrm{~Pa}$ and $n=4$ TEBVs for $0.4 \mathrm{~Pa}$; $0.1 \mathrm{~Pa}{ }^{\star} P=0.0262,{ }^{\star \star \star} P<0.0001 ; 0.4 \mathrm{~Pa}{ }^{\star} P=0.0146$, ${ }^{\star \star} P=$ 0.005 , ${ }^{* \star *} P<0.0001$ compared to control-/- by two-way ANOVA and Tukey post hoc test). $\mathbf{g}$ Migration of monocytes (cell tracker-red) in the TEBVs. Depth of monocytes into vessel wall from confocal z-sections (scale bar $100 \mu \mathrm{m}) . \mathbf{h}$ Experimental design of TEBV treatment with eLDL (40 h) with and without whole blood $(40 \mathrm{~h}$ ). i Quantification of monocyte accumulation in TEBVs after treatment with eLDL and whole blood as in panel $\mathrm{h}$ (mean \pm S.D., $n=4$ TEBVs, $P$ values obtained by two-way ANOVA and Tukey post hoc test)). $\mathbf{j}$-l. Oil-red O positive macrophage foam cells in TEBVs (scale bar: $100 \mu \mathrm{m}$ in (j) and $20 \mu \mathrm{m}$ in (k)). I Fibroblasts uptake of eLDL detected by Oil Red O staining for: control (i), $96 \mathrm{~h}$ of eLDL (ii), $96 \mathrm{~h}$ of eLDL+8 h of TNF $\alpha$ (iii), 8 days of recovery after eLDL treatment (iv) (scale bar: $50 \mu \mathrm{m}$ ).

molecule or cytokines produced and when evaluating drug responses. A limitation to any microphysiological system, either TEBV or microfluidic device, to simulate in vivo conditions for larger vessels is that dynamic similarity results in higher shear stresses than those occurring in human blood vessels, which may limit leukocyte adhesion and endothelial function. If, however, the focus is upon the shear stress acting on endothelium, then the Reynolds numbers and Womersley will be less than those in vivo, potentially leading to greater leukocyte adhesion and transmigration.

A novel observation of this work is that eLDL treatment of the TEBVs inhibited vasoconstriction as well as endothelial-mediated vasodilation, which was blocked by statins and partially inhibited by NF157. Evidence that modified LDL inhibits endothelialmediated vasodilation has been indirect, based largely on in vitro studies that oxidized LDL or its components inhibit nitric oxide production $^{64}$ and the anti-inflammatory effect of statins. Prior studies that examined the effect of modified LDL upon vessel vasoactivity used isolated arterial rings and were confined to short incubation times (45-60 min). One study did report that that arterial rings treated with oxidized LDL in vitro did have attenuated vasodilation following vasoconstriction with phenylephrine $^{65}$. Modified LDL had limited effects on vasoconstriction ${ }^{66-68}$, although one study found that oxidized LDL enhanced vasoconstriction $^{65}$. Differences between these studies and current results may be due to the duration of exposure or the type of LDL modification. These prior studies could not examine long-term recovery after exposure to modified LDL as we have shown.

This TEBV microphysiological system overcomes many of the previously discussed challenges of using animal models, by utilizing iPS or primary human cells where therapeutic effects can be tested directly. Furthermore, important hypotheses related to disease progression can be tested in this system, given the ability to control different aspects of the disease. For instance, it continues to be greatly debated if foam cells are derived from circulating monocytes being recruited to atheroprone sites, or if they are resident cells eventually transforming to foam cells, or a possible combination of the two $0^{69,70}$. Future experiments can provide macrophages as part of the construct or in circulation to help better understand how different methods of macrophage introduction change foam cell formation timing and consistency.

Other clinically relevant observation in our model relate to the timing of exposure, measured effect and eventual recovery from eLDL and TNFa exposure. eLDL induction of vessel inflammation was more long term compared to TNFa, with a more pronounced effect on ICAM-1 as compared to TNF primarily upregulation of VCAM-1. Importantly, after withdrawal of these factors, the vessel vasoactive response recovered. Lovastatin treatment in eLDL exposed vessels leads to a decrease in lesion development and adhesion molecules expression. This was not seen with TNFa, where changes in VCAM-1, ICAM-1 and ESelectin with Lovastatin treatment were not statistically significant. This possibly highlights the need for anti-inflammatory drugs that might be important to blocking the inflammatory specific component of atherosclerosis.

In summary, we used endothelialized arteriole-scale TEBVs to develop a model of early stage atherosclerosis in vitro. Through perfusion of enzyme-modified LDL, TNFa and monocytes in this system, the disease model of early stage atherosclerosis was established in vitro. Key features of this disease model included the dysfunction of vessels (vasoactivity and permeability), the inflammatory in vessel (increasing NO production and the activation of endothelial cells), the accumulation and migration of monocytes, and the formation of foam cells. Removal of eLDL caused partial regression of the disease. Furthermore, some novel results were observed, such as eLDL-induced dysfunction of vasoactivity, recovery of early stage atherosclerosis, and the effects of Lovastatin and NF157 in early stage atherosclerosis modeling. This work demonstrates the potential of this in vitro TEBV disease model

\section{Methods}

Cells isolation and culture. All primary human cell isolations were performed using a protocol approved by the Duke University Institutional Review Board (IRB). Human umbilical cord blood within $48 \mathrm{~h}$ of collection was obtained from the Carolina Cord Blood Bank. All patient identifiers were removed prior to receiving the cord blood. Primary human endothelial colony forming cells (ECFCs) were isolated and expanded from umbilical cord blood and used at passage 3-6 using an established protocol in our lab ${ }^{71}$. ECFCs were maintained in Endothelial Cell Medium (Cell Application) with 1\% Antibiotic-Antimycotic (Gibco).

Primary hNDF (Clonetics) were cultured in hNDF medium comprised of Dulbecco's Modified Eagle's Medium (DMEM) with $4.5 \mathrm{~g} / \mathrm{L}$ glucose (Gibco) supplemented with $10 \%$ HI-FBS (Hyclone), $1 \times$ Non-essential amino acids (NEAA, Gibco), $1 \%$ Pen/Strep, $1 \times$ Glutamax (Gibco), $1 \times$ sodium pyruvate $($ Gibco), and $0.1 \% \beta$-mercaptoethanol (Gibco). Cells in passages $4-10$ were used for all experiments.

Human Coronary Artery Smooth Muscle (hCASMCs) were purchased from Cell Applications, Inc. (San Diego, CA) and cultured in SMC media (Cell Applications 311-500). Cells were used to fabricate TEBVs at passage 6 or 7 .

Primary human monocytes were isolated from whole blood with Magnetic Assisted Cell Sorting (MACS, CD14 + Beads, Miltenyi Biotec). The cells were more than $90 \%$ CD $14+$ after isolation and were maintained in monocyte medium comprised of RPMI-1640 medium (Sigma) supplemented with 10\% heatinactivated FBS (Hyclone). To produce macrophages, $20 \mathrm{ng} / \mathrm{ml}$ GM-CSF (PeproTech) was added into the culture media for 3 days.

The human monocytic cell line U937 (Sigma) was maintained in RPMI-1640 medium (Sigma) supplemented with $10 \%$ FBS (Hyclone), $1 \times$ GlutaMAX-1 (Sigma).

Design and fabrication of the molds and perfusion chamber. The molds used in this work were created using acrylic and composed of 5 parts, which form the fabrication mold and prefusion chamber (Fig. S1). The TEBV (2 layers) fabrication mold is formed from parts A, B, and C. Part A housed the mandrels about which 
a
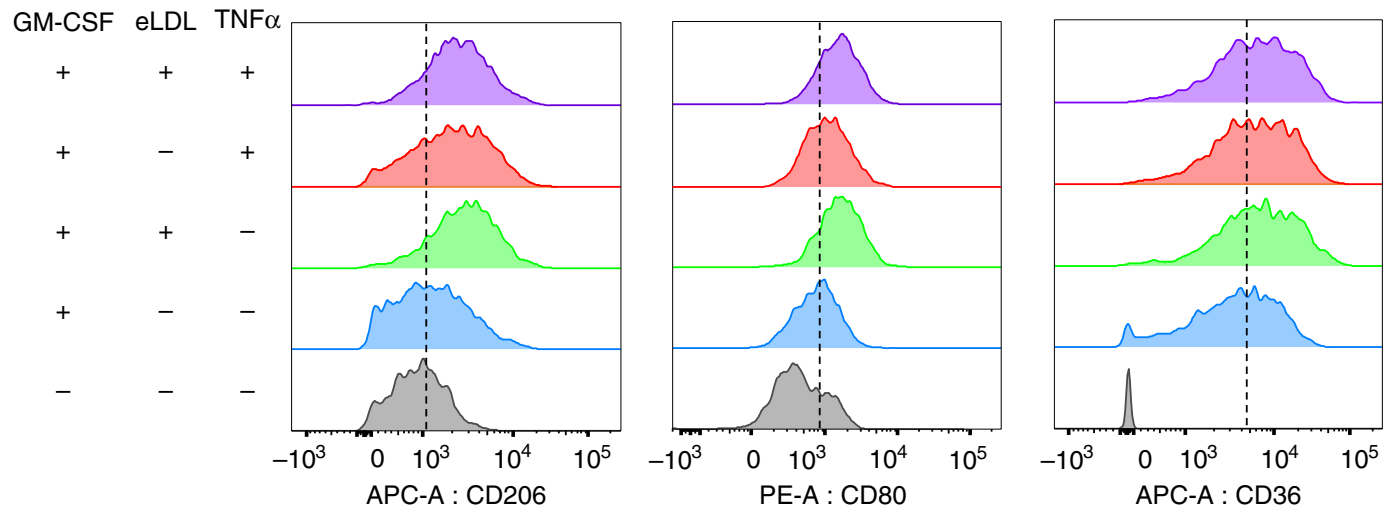

b
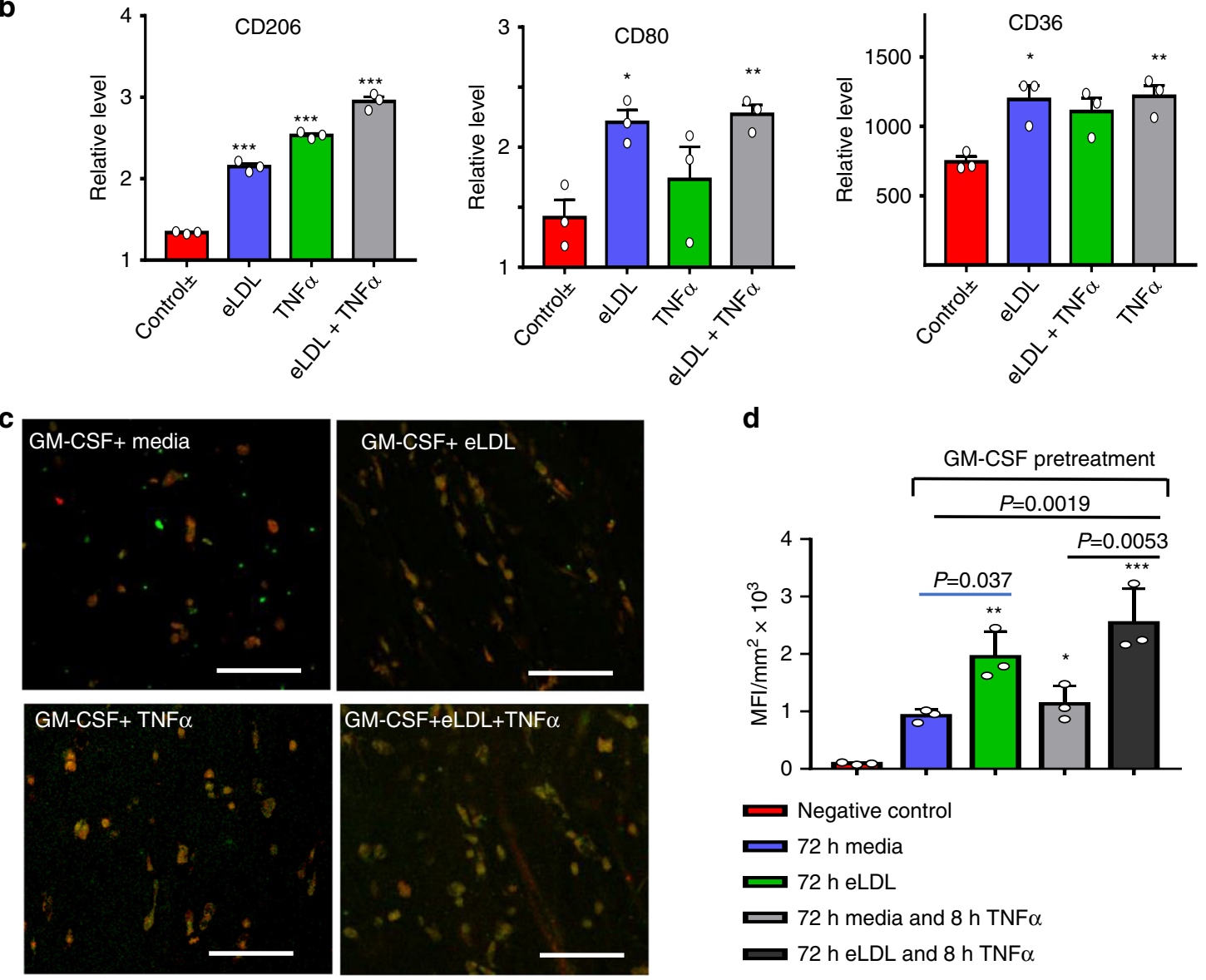

d
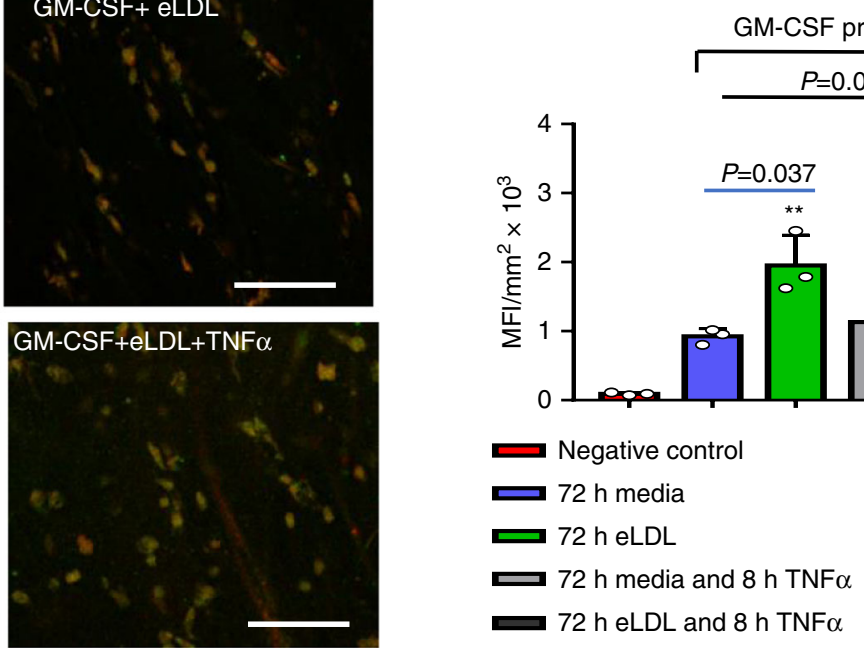

Fig. 7 Macrophage polarization in TEBVs after exposure to eLDL and/or TNFo. a Flow cytometry of primary human monocyte differentiation into macrophages with eLDL $\pm T N F \alpha$ treatment. $\mathbf{b}$ Quantification of the mean fluorescence intensity (MFI) of flow cytometry results. The relative level represents normalization to negative control-/-(no GM-CSF/no treatments), (mean \pm S.D., $n=3$ independent wells from two monocyte isolations, CD206: ${ }^{\star \star} P<$ 0.0001; CD80: ${ }^{\star} P=0.0397,{ }^{\star \star} P=0.0267 ; \mathrm{CD} 36:{ }^{\star} P=0.0187,{ }^{\star} P=0.0143$, compared to control $+/-=\mathrm{GM}-\mathrm{CSF}$ control/no treatments by one-way ANOVA and Tukey post hoc test). c Characterization of primary monocytes derived macrophages in perfused TEBVs with GM-CSF pretreatment and addition of eLDL for $96 \mathrm{~h}$ with or without $8 \mathrm{~h}$ TNF $\alpha$ treatment; fluorescence images of, monocytes-cell tracker red, CD80 + monocytes-green (scale bar $100 \mu \mathrm{m}$ ).

d Quantification of mean fluorescence intensity (MFI) per cell of CD80 + monocytes (green signal) based on the images in panel (c) (mean \pm S.D., $n=3$ TEBVs, ${ }^{\star} P=0.034,{ }^{\star \star} P=0.00066,{ }^{\star \star \star} P<0.0001$ compared to negative control by one-way ANOVA and Tukey post hoc test).

TEBVs were made and is used in both the fabrication mold and prefusion chamber. There are four steel hollow mandrels (outer diameter $0.63 \mathrm{~mm}$, inner diameter 0.33 $\mathrm{mm}$ ) at opposite sides of part A, which are mirror reflections of each other and link the assembled chamber to the perfusion tubing and pump. In the fabrication step, the halves of each mandrel are inserted into the chamber (Part A) and brought into contact with each other (Fig. S1ai and S1bi). Part B forms the top layer of the seeding mold with inlets/outlets and grooves, and part $\mathrm{C}$ is the bottom layer of the seeding mold with grooves (Suppl Fig. S1aii and S1bii). The grooves on the top and bottom layers each form four semicircular channels (diameter $2.2 \mathrm{~mm}$, length 24 $\mathrm{mm}$ ) to be used as molds. Once the high-density collagen containing the hNDFs is added and gelled, parts B and C are removed, and the collagen TEBVs are dehydrated. Then the mandrels are drawn out forming a lumen. Following fixation of the collagen tubing on the mandrels, two new flat covers are added (parts D and E) and the final perfusion chamber is completed. The steel mandrels are used for perfusion, with one side acting as the media inlet, and the other as the outlet. To fabricate the 3-layer TEBVs, parts A, F, G are first assembled to produce a mold with diameter $1.4 \mathrm{~mm}$ and length $24 \mathrm{~mm}$ (Fig. S1d). After seeding the mixture of hSMCs and collagen, the middle layer of TEBVs is allowed to gel. Then, parts F\&G 
a (i)

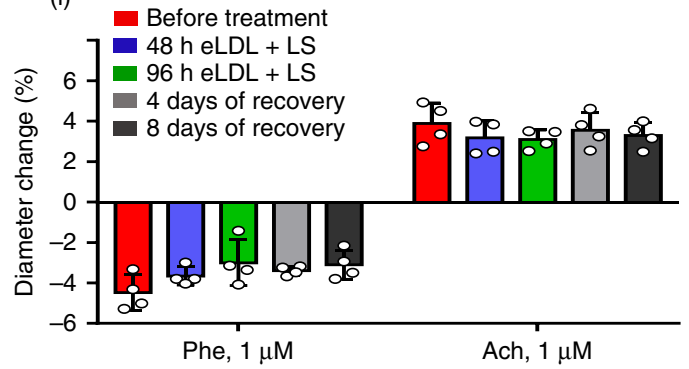

b (i)

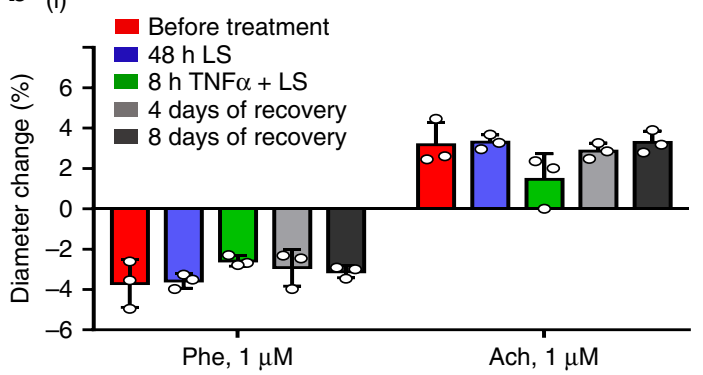

(ii)

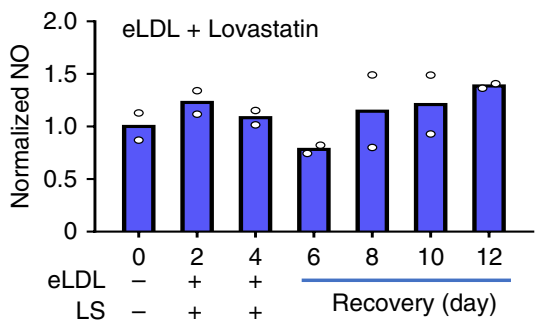

(ii)

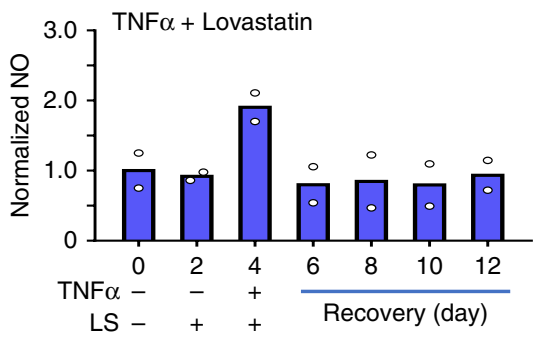

C

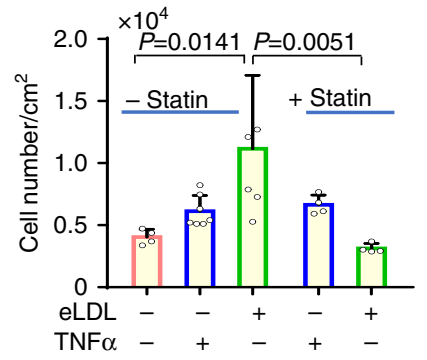

d

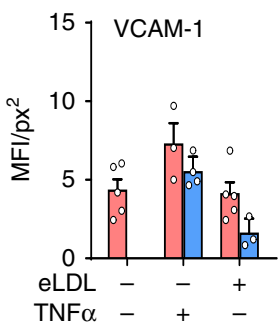

eLDL

eLDL + LS
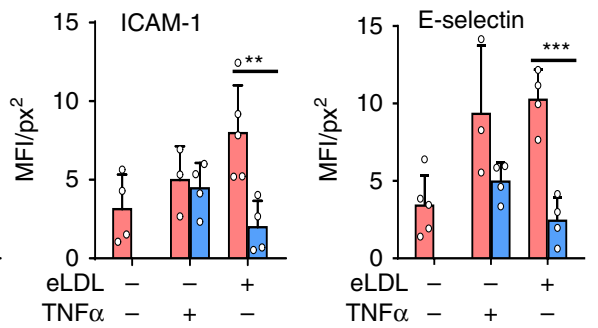

e
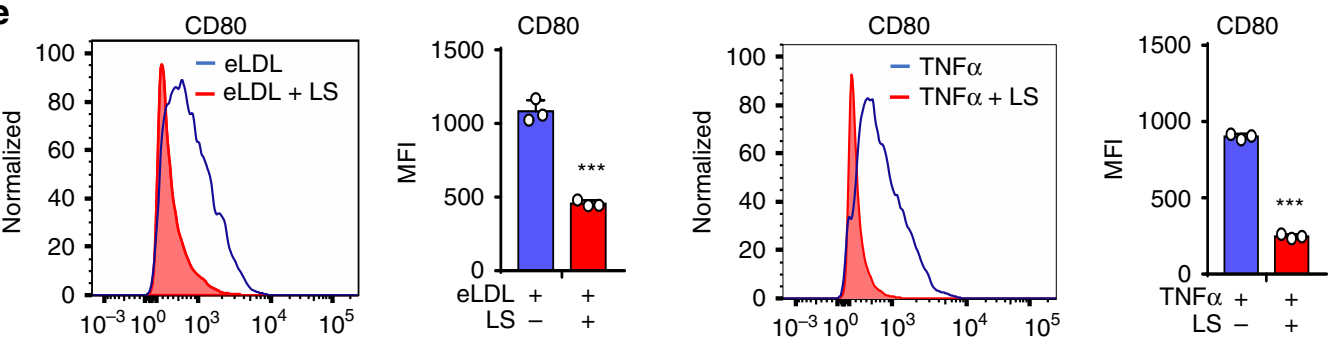

f
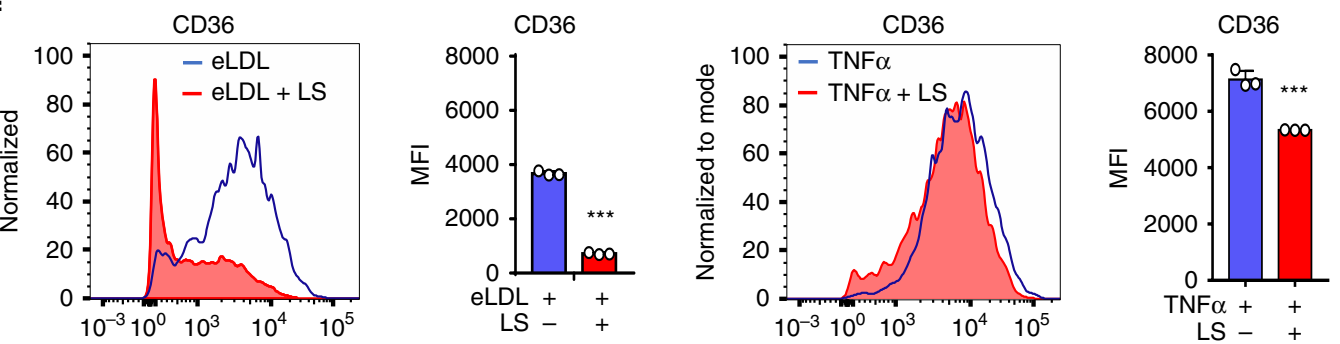

are removed and parts $\mathrm{B} \& \mathrm{C}$ are attached to part $\mathrm{A}$ to form the larger diameter mold as described above. Followed by seeding hNDFs and collagen mixture, the outer layer (diameter $2.9 \mathrm{~mm}$ ) are formed. For both designs, after dehydration and suture of the TEBVs on mandrels, endothelial cells are perfused through the vessel lumen and allowed to adhere.

Fabrication, endothelialization, and perfusion of TEBVs. TEBVs were fabricated from collagen which underwent plastic compression to remove water and increase the mechanical strength ${ }^{72}$. High concentration rat tail collagen I (Corning, 8.2-9.4

$\mathrm{mg} / \mathrm{ml}$ ) was diluted to $7 \mathrm{mg} / \mathrm{ml}$ mixture on ice using $10 \times$ Dulbecco's Modified Eagle's Medium (Sigma, final concentration $1 \times$ in mixture), $1 \mathrm{M}$ sodium hydroxide (Sigma, final pH 8.5) and the suspension of hNDFs (final cell density $10^{6}$ cells $/ \mathrm{ml}$ ). The gel mixture was immediately injected into the seeding mold containing the four channels $(180 \mu \mathrm{l} /$ channel) and surrounding annular tubes which served as a mandrel (Fig. S1bi) and incubated at $37^{\circ} \mathrm{C}$ for $30 \mathrm{~min}$. The gelled collagen was dehydrated by exposing each side of the TEBVs to KimWipes (Whatman) 5 times. This removed about $90 \%$ of the water from the collagen gel (Fig. S2). Finally, the mandrels in the gels were drawn out $5-6 \mathrm{~mm}$ on each side to generate a channel in 
Fig. 8 Lovastatin blocks formation of early atherosclerosis in TEBVs. Perfusion of $1 \mu M$ Lovastatin (LS) with $50 \mu g / m l$ eLDL blocks eLDL-mediated altered vasoactivity (a-i) (mean \pm S.D., $n=4$ TEBVs, Phe: phenylephrine, Ach: acetylcholine) and NO production (a-ii) in TEBVs (mean \pm S.D., $n=2$ from 8 TEBVs, $\mathrm{R}$ means recovery). b Lovastatin $(1 \mu \mathrm{M})$ blocks the $50 \mathrm{U} / \mathrm{ml}$ TNF $\alpha$ mediated dysfunction of vasoactivity (i, mean \pm S.D., $n=3$ TEBVs, Phe: phenylephrine, Ach: acetylcholine) and NO production in TEBVs (ii, mean \pm S.D., $n=2$ from 8 TEBVs, R means recovery). c Lovastatin block eLDL-mediated monocyte accumulation in TEBVs (mean \pm S.D., $n=4,7,5,4,4$ TEBVs by two-way ANOVA). $\mathbf{d}$ Lovastatin inhibits ICAM-1 and E-selectin expression on endothelial cells in TEBVs (mean \pm S.D., $n=5,3,4,5,3$ TEBV s for VCAM-1 accordingly, $n=4,3,4,5,4$ TEBVs for ICAM- 1 accordingly, $n=5,3,4,4,4$ TEBV s for E-Selectin accordingly, ${ }^{\star \star} P=0.0097,{ }^{\star \star \star} P=0.0007$ by two-way ANOVA and Tukey post hoc test, MFI = mean fluorescence intensity). e Lovastatin (LS) blocks primary monocyte differentiation into macrophages, flow cytometry testing of CD80 (mean \pm S.D., $n=3$ independent wells from one monocyte isolations, ICAM-1: ${ }^{\star \star} P=0.00016$, E-Selectin: ${ }^{\star \star \star} P<0.0001$ by Student's $t$ test, MFI = mean fluorescence intensity). $\mathbf{f}$ Lovastatin (LS) blocks primary monocytes activation, flow cytometry testing of CD36 (mean \pm S.D., $n=3$ independent wells, ${ }^{\star \star \star} P<0.0001$ by Student's $t$ test, MFI $=$ mean fluorescence intensity). (Flow rate: $0.5 \mathrm{ml} / \mathrm{min}$ per TEBV $(0.4 \mathrm{~Pa})$ for vasoactivity testing and $0.125 \mathrm{ml} / \mathrm{min}(0.1 \mathrm{~Pa})$ for monocyte accumulation).

each TEBV. The ends of the newly generated vessels were tied using 4-0 silk sutures around the mandrel ends to eliminate leakage (Fig. S1avi). The hSMCs density in collagen was $10^{6}$ cells $/ \mathrm{ml}$. The seeding volume of hSMC/collagen mixture was $40 \mu \mathrm{l} /$ channel and the seeding volume of hNDF/collagen mixture layer was $140 \mu \mathrm{l} /$ channel.

The final culture chamber was assembled, and media was added to the chamber (Figs. Slav and S1c xiii). Next, $50 \mu \mathrm{l}$ of an ECFC suspension $\left(8 \times 10^{6} \mathrm{cells} / \mathrm{ml}\right)$ was injected through the lumen of each TEBV. The chamber was sealed and rotated at 10 rotations $/ \mathrm{h}$ for $45 \mathrm{~min}$ at $37^{\circ} \mathrm{C}$ to allow for a uniform distribution of endothelial cells. Then the chip was attached to a flow loop containing a peristaltic pump (Masterflex) with a multi-channel pump head (Cole-Parmer) to create continuous flow through the four TEBVs in each chip. The flow rate of the pump was set to $0.5 \mathrm{ml} / \mathrm{min}$ per TEBV, which produced a shear stress of $0.4 \mathrm{~Pa}$ based on an average TEBV inner diameter of $647.5 \pm 45.6 \mu \mathrm{m}$. For monocyte perfusion experiments, the flows of 0.5 $\mathrm{ml} / \mathrm{min}$ per vessel $(0.4 \mathrm{~Pa})$ and $0.125 \mathrm{ml} / \mathrm{min}$ per vessel $(0.1 \mathrm{~Pa})$ were used to enable monocyte adhesion, which are comparable to the physiological shear stress ${ }^{63}$. The total perfusion volume was $3 \mathrm{ml}$ in main vessel loop and $4 \mathrm{ml}$ in the side loop (Fig. 1b). EGM media was used for the finished TEBVs and was changed every 2 days.

Permeability of TEBVs to macromolecules. Permeability assays were performed in acellular collagen constructs and in TEBVs. Fluorescein isothiocyanate (FITC) labeled goat IgG (Invitrogen) and $500 \mathrm{kDa}$ FITC-dextran (Sigma) were diluted to $10 \mu \mathrm{g} / \mathrm{ml}$ and $20 \mu \mathrm{g} / \mathrm{ml}$, respectively, in PBS and injected into the TEBV lumen. Serial fluorescence images with the same exposure time were taken every 5 min for up to $20 \mathrm{~min}$. Then the permeability of TEBVs was calculated using equation ${ }^{73}$ :

$$
P=\frac{1}{\Delta I}\left(\frac{\mathrm{d} I}{\mathrm{~d} t}\right)_{t=0} \frac{r}{2},
$$

where $\Delta I$ is the change in total fluorescence intensity upon addition of labeled molecule $(t=0)$-Background signal; $\left(\frac{\mathrm{d} d}{\mathrm{~d} t}\right)_{t=0}$ is the initial rate of transport of fluorescent dextran from the vessel lumen into the vessel, which can be approximated as $(\mathrm{d} I / \mathrm{d} t)_{t=0} \approx\left(I_{t}-I_{(t=0)}\right) / t$, where $I_{\mathrm{t}}$ is the intensity outside the vessel at time $t, I_{t=0}$ is the intensity outside the vessel at time $t=0 ; r$ is the radius of the lumen, which is estimated from width $/ 2$ of the fluorescent region at $t=0$. Based on published values for the hydraulic permeability of collagen gels undergoing plastic compression ${ }^{74}\left(10^{-14} \mathrm{~m}^{2}\right)$, the Peclet number for eLDL, which measures the relative value of the eLDL diffusion time to convection time is «1, indicating that the measured permeability is a diffusive permeability.

\section{Preparation of eLDL, TNF $\boldsymbol{\alpha}$, and Lovastatin solutions. Aliquots of human} plasma LDL were prepared by measuring the protein concentration of LDL (Lee Biosolutions) using the Lowry Protein Assay ${ }^{75}$ and then diluting in a $10 \%$ sucrose $(\mathrm{w} / \mathrm{v})$ saline solution $(150 \mathrm{mM} \mathrm{NaCl}, 0.24 \mathrm{mM}$ EDTA, $\mathrm{pH}$ 7.4) to achieve a final concentration of $10 \mathrm{mg} / \mathrm{ml}$. The sucrose enabled aliquots to be stored at $-80^{\circ} \mathrm{C}$ without loss of properties ${ }^{75}$. Enzyme modification of LDL was adapted from the method of Chellan et al. ${ }^{46} 7 \mu \mathrm{g}$ of trypsin (Sigma, T4049) and $12 \mu \mathrm{g}$ of cholesterol esterase per mg LDL protein are added and incubated for $16 \mathrm{~h}$ at $37^{\circ} \mathrm{C}$. Next, $24 \mu \mathrm{g}$ trypsin and $29 \mu \mathrm{g}$ cholesterol esterase per $\mathrm{mg}$ of LDL protein are added and incubated for $48 \mathrm{~h}$ at $37^{\circ} \mathrm{C}$. In both cases, cholesterol esterase is administered $6 \mathrm{~h}$ after adding trypsin. After incubation, the eLDL solution is dialyzed again in PBS, $\mathrm{pH} 7.4$ for $24 \mathrm{~h}$. The eLDL is filter sterilized, its final protein concentration is measured, and stored at $4{ }^{\circ} \mathrm{C}$. Particle size is characterized via dynamic light scattering (Malvern Zetasizer LS). LDL was oxidized by incubation with $10 \mu \mathrm{M}$ $\mathrm{CuSO}_{4}$ for $48 \mathrm{~h}^{46}$.

TNFa (Sigma) was dissolved at a concentration of $10 \mu \mathrm{g} / \mathrm{ml}$ in sterile DPBS without calcium and magnesium. This concentration is equivalent to enzymatic activity of $200 \mathrm{U} / \mu \mathrm{l}$. Stocks were kept frozen for 3 months before expiration and aliquots were used once with only one freeze thaw cycle. Lovastatin (Sigma) was dissolved in a solution of $40 \%$ ethanol (95-100\%) and $60 \% 0.1 \mathrm{~N} \mathrm{NaOH}$. After heating at $50^{\circ} \mathrm{C}$ for $2 \mathrm{~h}$, the solution was neutralized with $\mathrm{HCI}$ to a $\mathrm{pH}$ of approximately 7.2 and brought up to a volume of $1 \mathrm{ml}$ with distilled water. The stock concentration of Lovastatin is $0.0198 \mathrm{mM}$.

\section{TEBV burst pressure, ultimate tensile stress, vasoactivity and nitric oxide} (NO) production. The burst pressure, ultimate tensile stress (UTS), vasoactivity, and NO production testing were preformed following established protocols in our $\mathrm{lab}^{31}$. Briefly, the burst pressure is tested in each TEBV with one end sealed, and an infusion of PBS at the other end until failure. Pressure was measured using a differential pressure gauge (Keller) and images were obtained to record the diameter. Then the ultimate tensile stress was calculated using the following equation:

$$
\mathrm{UTS}=P \times \mathrm{D} / 2 t
$$

where $P$ is the burst pressure, $D$ is the diameter of vessel lumen under burst pressure dilation, and $t$ is the thickness of the vessel wall that was calculated using $\left(D_{\text {outer }}-D_{\text {lumen }}\right) / 2$ under burst pressure dilation. The lumen diameter, $D_{\text {lumen }}$, was determined using the value measured from histology for unpressurized vessels and the conservation of mass.

The vasoactivity of TEBVs was evaluated by placing the TEBV chip under a stereoscope (Amscope, software "ISCapture v3.6") at $9 \times$ amplification, recording an image of the initial outer diameter, and adding $1 \mu \mathrm{M}$ phenylephrine (Sigma) to the flow circuit. After $5 \mathrm{~min}$, the outer diameter was recorded and acetylcholine (Sigma) was added to the perfusion media for $5 \mathrm{~min}$ at a final concentration of $1 \mu \mathrm{M}$ to assess vasodilation. The outer diameter change of the TEBVs was analyzed using Image J (NIH). For NO production testing, the total concentration of nitrite and nitrate in the prefusion media was assessed using a Griess reagent assay kit (Pierce). Absorbance at $540 \mathrm{~nm}$ was measured using a Quant microplate reader (Bio-Tek). Samples were normalized to blank media controls.

Monocytes perfusion, accumulation, and migration. For monocyte perfusion, the TEBVs were perfused for one week to mature, then monocytes were added in the vessel loop only at $1 \times 10^{6}$ cells $/ \mathrm{ml}$ for U937 cells and $2.5 \times 10^{6}$ cells $/ \mathrm{ml}$ for primary monocytes. Total perfusion volume of the vessel loop was $3 \mathrm{ml}$. To measure monocyte accumulation and migration, monocytes were labeled with cell tracker red-CMTPX (Life Tech) before addition to the perfusion loop. At the end of monocyte perfusion, the TEBV lumen was washed with PBS gently to remove unattached cells. Then the TEBVs were fixed with $4 \%$ Paraformaldehyde (PFA) solution for one hour. The TEBV is opened en face and compressed between two coverslips. The accumulation of monocytes is analyzed based on fluorescence images and the migration of monocytes is analyzed from confocal images at different depths into the TEBV from the endothelial surface. For human whole blood perfusion, fresh collected umbilical cord blood with $25-30 \%$ citrate-phosphatedextrose (CPD) is used to replace the perfusion media in vessel loop. $1 \times 10^{6}$ cells/ $\mathrm{ml}$ of the cell tracker-CMTPX labeled U937 are added into whole blood and perfusion for $40 \mathrm{~h}$. The side loop contained only media.

Flow cytometry, immunofluorescence, and oil-red staining. For flow cytometry, monocytes were stained with fluorescently labeled antibodies, including PE antihuman CD80 (Biolegend, 1:50), APC anti-human CD36 (Biolegend, 1:50), Pacific Blue $^{\mathrm{m}}$ anti-human CD206 (BD Pharmingen, 1:25) or Pacific Blue anti-human CD14 (Biolegend, 1:50), for $20 \mathrm{~min}$ on ice. The APC Mouse IgG2a (Biolegend, 1:50), PE Mouse IgG1(Biolegend, 1:50), and Pacific Blue ${ }^{\mathrm{mt}}$ Mouse IgG1 (Biolegend. 1:50) were used to stain the cells as isotype control, which was used to set the selected gate during testing. Then stained cells were collected by FACSCanto (BD Bioscience) and analyzed by FlowJo (Treestar, MAC version, v9.3.2) software. The gating strategy is shown in Fig. S11. For immunostaining, TEBVs are perfused and gently washed using PBS then fixed in $4 \%$ paraformaldehyde for $60 \mathrm{~min}$ at room temperature. Following fixation, samples are washed in PBS then blocked in blocking buffer (PBS $+10 \%$ goat serum $+5 \% \mathrm{BSA}$ ) for $2 \mathrm{hr}$ at room temperature. Cross-sections are obtained on a cryostat (Leica CM3050). The following primary antibodies were used for vessel characterization: CD31 (BD, 1:200), $\alpha$-smooth muscle actin (aSMA, Abcam, 1:150), smooth muscle myosin heavy chain 11 (MHC11, Abcam, 1:100), CD80 
a Day 1-7: TEBV maturation and perfusion

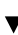

Day7-11: 96 h $50 \mu \mathrm{g} / \mathrm{ml}$ eLDL

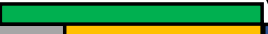

V

Recovery for 8 days

Day7-day 19: test vasoactivity every 2 days
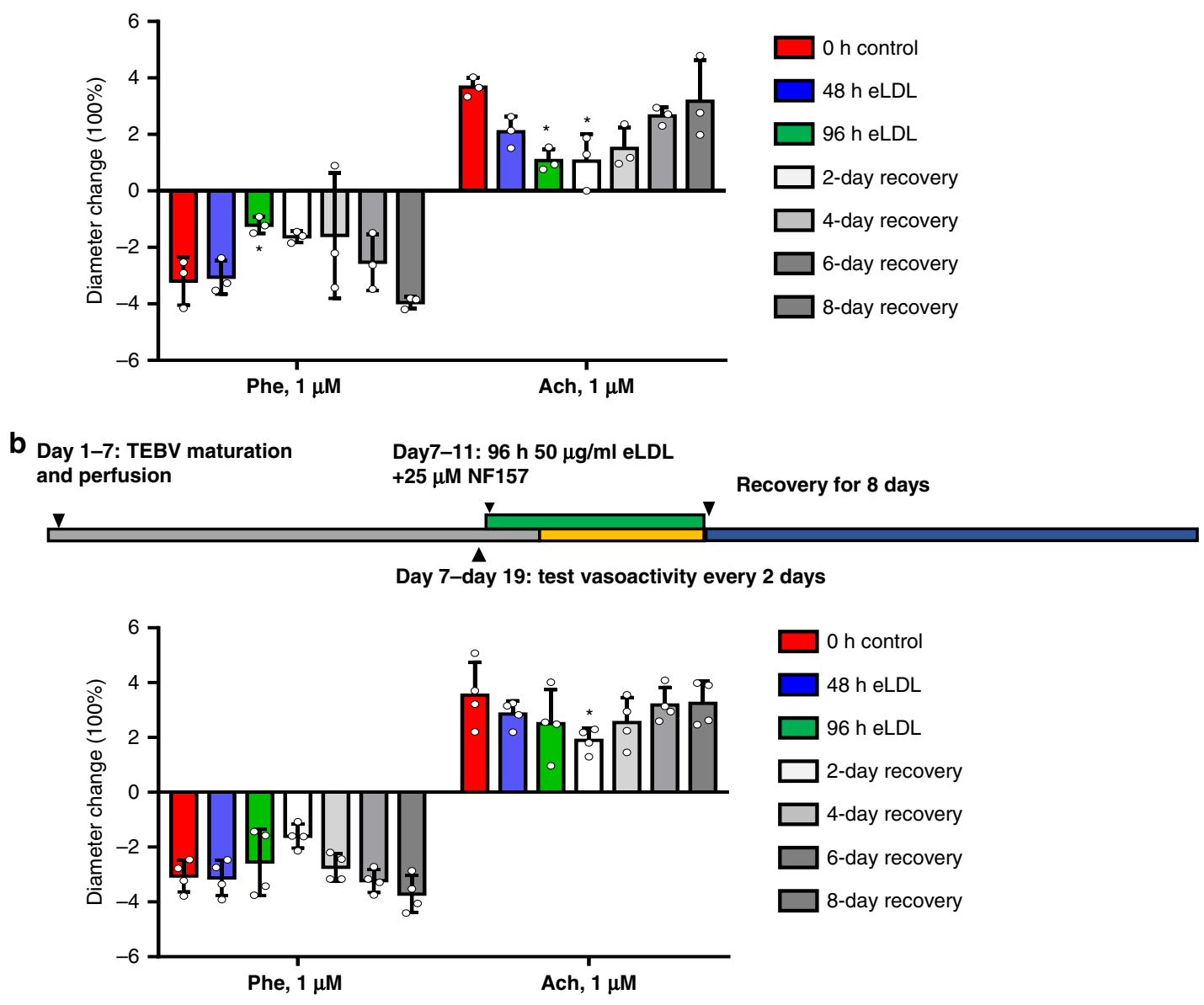

C

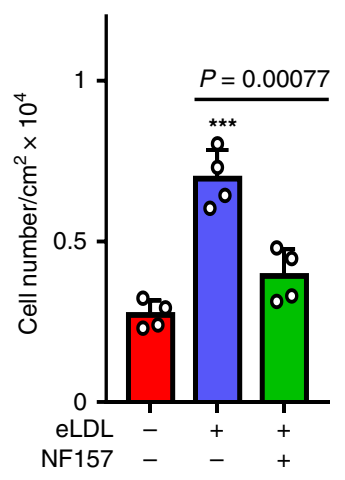

d

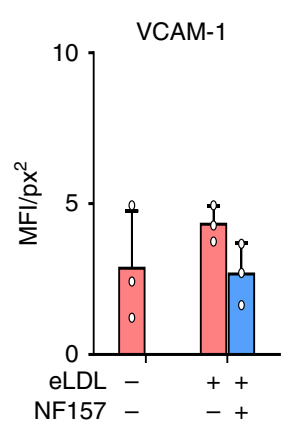

$+\mathrm{NF} 157$

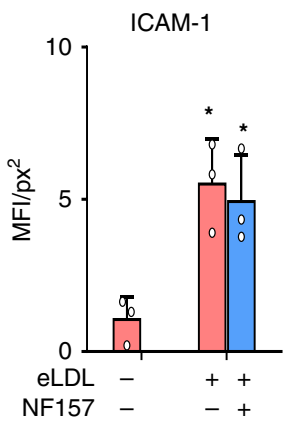

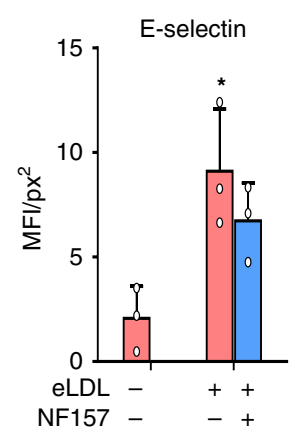

Fig. 9 NF157 block events in early atherosclerosis in TEBVs. a Perfusion of TEBVs with $50 \mu \mathrm{g} / \mathrm{ml}$ eLDL reduces vasoconstriction and vasodilation, but the response recovers 8 days after removal of eLDL (mean \pm S.D., $n=4$ TEBVs, ${ }^{\star} P E$ : $P=0.01408$, Ach: ${ }^{\star} P=0.01543$ to control by two-way ANOVA and Tukey post hoc test). $\mathbf{b}$ Addition of $25 \mu \mathrm{M}$ NF157 with $50 \mu \mathrm{g} / \mathrm{ml}$ reduces the inhibition of vasoactivity and leads to a more rapid recovery after removal of eLDL (mean \pm S.D., $n=4$ TEBVs, ${ }^{\star} P=0.01369$ to control by two-way ANOVA and Tukey post hoc test). c NF157 block eLDL-mediated monocyte accumulation in TEBVs (mean $\pm \mathrm{S}$. D., $n=4$ TEBVs, ${ }^{\star} P<0.05,{ }^{\star \star \star} P<0.0001$ to control by two-way ANOVA). d NF157 does not inhibit ICAM-1 and E-selectin expression on endothelial cells in TEBVs (mean \pm S.D., $n=3$ TEBVs, ICAM-1: ${ }^{\star} P=0.0136$ control vs. eLDL, ${ }^{\star} P=0.0252$ control vs. eLDL $+N F 157$; E-selectin ${ }^{\star} P=0.0181$ control vs. eLDL by twoway ANOVA and Tukey post hoc test, MFI = mean fluorescence intensity; Flow rate: $0.4 \mathrm{~Pa}$ to vasoactivity testing and $0.1 \mathrm{~Pa}$ for monocyte accumulation).

(BioLegend, 1:100), VCAM-1 (Santa Cruz Biotechnology, 1:200), ICAM-1 (Santa Cruz Biotechnology, 1:200), E-selectin (Santa Cruz Biotechnology, 1:200). Then the primary antibodies were treated with fluorescently labeled secondary antibodies: 488-goat anti mouse IgG, 488-goat anti rabbit IgG, 546-goat anti mouse IgG, 546-goat anti rabbit IgG, 633-goat anti mouse (1:200) (Life Technologies) and Hoechst dye (1:1000) to stain nuclei. Images were acquired using a Leica SP5 inverted confocal microscope (software "LAS AF v2.7.3.9723"). Oil Red staining was performed by using standard protocols on vessels fixed in $4 \%$ paraformaldehyde. The images were acquired using a fluorescence microscope (Nikon model TE2000-U, software "NIS-Elementa AR v3.2"). 
RNA isolation and reverse transcriptase-PCR analysis. The primer sequences (Table S1) are obtained from PubMed and are generated using the online design program Primer-Blast. Total RNA was isolated from the entire TEBV directly using RNeasy Fibrous Tissue Mini Kit (QIAGEN). The purity and concentration of RNA were measured using a Nano-Drop Spectrophotometer. For reverse transcription of RNA into cDNA, $250 \mathrm{ng}$ RNA from the entire TEBV is used for each sample. Reverse transcription was performed using the iScript cDNA Synthesis Kit (BioRad). The PCR reaction was mixed by following the protocol of the iQ SYBR Green Supermix (Bio-Rad). RT-PCR was performed using a CFX Connect RealTime PCR Detection System (Bio-Rad).

Statistics and reproducibility. Data were analyzed using Microsoft Excel, Originlab, and Graphpad Prism. Results are presented as mean \pm S.D. unless noted otherwise. Statistical significance is determined by Student's $t$ test between two groups and ANOVA with a post hoc Tukey test for multiple groups. A value of $p<$ 0.05 was considered statistically significant. All the images were confirmed or observed for at least 3 separate experiments in this work.

Reporting summary. Further information on research design is available in the Nature Research Reporting Summary linked to this article.

\section{Data availability}

The authors declare that all data supporting the findings of this study presented in the graphs are available in Source Data file and other results or can be requested from the authors. Source data are provided with this paper.

Received: 18 September 2019; Accepted: 1 October 2020; Published online: 27 October 2020

\section{References}

1. Moore, K. J. \& Tabas, I. Macrophages in the pathogenesis of atherosclerosis. Cell 145, 341-355 (2011).

2. Yahagi, K. et al. Pathophysiology of native coronary, vein graft, and in-stent atherosclerosis. Nat. Rev. Cardiol. 13, 79-98 (2016).

3. Gimbrone, M. A. Jr \& Garcia-Cardena, G. Endothelial cell dysfunction and the pathobiology of atherosclerosis. Circ. Res. 118, 620-636 (2016).

4. Parks, B. W. \& Lusis, A. J. Macrophage accumulation in atherosclerosis. N. Engl. J. Med 369, 2352-2353 (2013).

5. Robbins, C. S. et al. Local proliferation dominates lesional macrophage accumulation in atherosclerosis. Nat. Med. 19, 1166-1172 (2013).

6. Chistiakov, D. A., Melnichenko, A. A., Myasoedova, V. A., Grechko, A. V. \& Orekhov, A. N. Mechanisms of foam cell formation in atherosclerosis. J. Mol. Med. (Berl.) 95, 1153-1165 (2017).

7. Back, M. \& Hansson, G. K. Anti-inflammatory therapies for atherosclerosis. Nat. Rev. Cardiol. 12, 199-211 (2015).

8. Skeoch, S. \& Bruce, I. N. Atherosclerosis in rheumatoid arthritis: is it all about inflammation? Nat. Rev. Rheumatol. 11, 390-400 (2015).

9. Carbone, F. et al. Atherosclerosis in rheumatoid arthritis: promoters and opponents. Clin. Rev. Allergy Immunol. 58, 1-14 (2020).

10. Lauper, K. \& Gabay, C. Cardiovascular risk in patients with rheumatoid arthritis. Semin. Immunopathol. 39, 447-459 (2017).

11. Elshabrawy, H. A. et al. The pathogenic role of angiogenesis in rheumatoid arthritis. Angiogenesis 18, 433-448 (2015).

12. Ridker, P. M. et al. Antiinflammatory therapy with canakinumab for atherosclerotic disease. N. Engl. J. Med 377, 1119-1131 (2017).

13. Tardif, J.-C. et al. Efficacy and safety of low-dose colchicine after myocardial infarction. N. Engl. J. Med. 381, 2497-2505 (2019).

14. Ridker, P. M. et al. Low-dose methotrexate for the prevention of atherosclerotic events. N. Engl. J. Med. 380, 752-762 (2019).

15. Getz, G. S. \& Reardon, C. A. Animal models of atherosclerosis. Arterioscler Thromb. Vasc. Biol. 32, 1104-1115 (2012).

16. Getz, G. S. \& Reardon, C. A. Do the Apoe ${ }^{-1-}$ and $\mathrm{Ldll}^{-/-}$mice yield the same insight on atherogenesis? Arterioscler Thromb. Vasc. Biol. 36, 1734-1741 (2016).

17. Getz, G. S., Vanderlaan, P. A. \& Reardon, C. A. The immune system and murine atherosclerosis. Curr. Drug Targets 8, 1297-1306 (2007).

18. Getz, G. S. \& Reardon, C. A. Diet and murine atherosclerosis. Arterioscler Thromb. Vasc. Biol. 26, 242-249 (2006).

19. Truskey, G. A. Human microphysiological systems and organoids as in vitro models for toxicological studies. Front Public Health 6, 185 (2018).

20. Rothbauer, M., Rosser, J. M., Zirath, H. \& Ertl, P. Tomorrow today: organ-ona-chip advances towards clinically relevant pharmaceutical and medical in vitro models. Curr. Opin. Biotechnol. 55, 81-86 (2019).

21. Chrobak, K. M., Potter, D. R. \& Tien, J. Formation of perfused, functional microvascular tubes in vitro. Microvasc. Res 71, 185-196 (2006).
22. Wang, X. et al. Engineering anastomosis between living capillary networks and endothelial cell-lined microfluidic channels. Lab Chip 16, 282-290 (2016).

23. Wang, X., Sun, Q. \& Pei, J. Microfluidic-based 3d engineered microvascular networks and their applications in vascularized microtumor models. Micromachines (Basel) 9, 493 (2018).

24. Zheng, Y. et al. In vitro microvessels for the study of angiogenesis and thrombosis. Proc. Natl Acad. Sci. USA 109, 9342-9347 (2012).

25. Polacheck, W. J. et al. A non-canonical Notch complex regulates adherens junctions and vascular barrier function. Nature 552, 258-262 (2017).

26. Menon, N. V., Tay, H. M., Wee, S. N., Li, K. H. H. \& Hou, H. W. Microengineered perfusable 3D vasculatures for cardiovascular diseases. Lab Chip 17, 2960-2968 (2017).

27. Zheng, W. et al. An early-stage atherosclerosis research model based on microfluidics. Small 12, 2022-2034 (2016).

28. Pandian, N. K., Mannino, R. G., Lam, W. A. \& Jain, A. Thrombosis-on-a-chip: prospective impact of microphysiological models of vascular thrombosis. Curr. Opin. Biomed. Eng. 5, 29-34 (2018).

29. Atchison, L. et al. iPSC-derived endothelial cells affect vascular function in a tissue engineered blood vessel model of Hutchinson-Gilford Progeria syndrome. Stem Cell Rep. 14, 325-337 (2020).

30. Atchison, L., Zhang, H., Cao, K. \& Truskey, G. A. A tissue engineered blood vessel model of Hutchinson-Gilford Progeria syndrome using human iPSCderived smooth muscle cells. Sci. Rep. 7, 8168 (2017).

31. Fernandez, C. E. et al. Human vascular microphysiological system for in vitro drug screening. Sci. Rep. 6, 21579 (2016).

32. Spieker, L. E., Noll, G., Ruschitzka, F. T., Maier, W. \& Luscher, T. F. Working under pressure: the vascular endothelium in arterial hypertension. J. Hum. Hypertens. 14, 617-630 (2000).

33. Scicchitano, P. et al. The role of endothelial dysfunction and oxidative stress in cerebrovascular diseases. Free Radic Res. 53, 579-595 (2019).

34. Victor, V. M. et al. Oxidative stress, endothelial dysfunction and atherosclerosis. Curr. Pharm. Des. 15, 2988-3002 (2009).

35. Rubanyi, G. M. The role of endothelium in cardiovascular homeostasis and diseases. J. Cardiovasc Pharm. 22, S1-S14 (1993).

36. Sudano, I. et al. Protection of endothelial function: targets for nutritional and pharmacological interventions. J. Cardiovasc Pharm. 47, S136-S150 (2006). discussion S172-136.

37. Chang, H. et al. Improved endothelial function of endothelial cell monolayer on the soft polyelectrolyte multilayer film with matrix-bound vascular endothelial growth factor. ACS Appl. Mater. Interfaces $\mathbf{8}$, 14357-14366 (2016).

38. Kannan, R. Y., Salacinski, H. J., Butler, P. E., Hamilton, G. \& Seifalian, A. M Current status of prosthetic bypass grafts: a review. J. Biomed. Mater. Res. B Appl. Biomater. 74, 570-581 (2005).

39. Sindram, D. et al. Collagen-elastin ratio predicts burst pressure of arterial seals created using a bipolar vessel sealing device in a porcine model. Surgical Endosc. 25, 2604-2612 (2011).

40. Sundaram, S. \& Niklason, L. E. Smooth muscle and other cell sources for human blood vessel engineering. Cells Tissues Organs 195, 15-25 (2011)

41. Poh, M. et al. Blood vessels engineered from human cells. Lancet 365, 2122-2124 (2005)

42. Steinbrecher, U. P., Parthasarathy, S., Leake, D. S., Witztum, J. L. \& Steinberg D. Modification of low density lipoprotein by endothelial cells involves lipid peroxidation and degradation of low density lipoprotein phospholipids. Proc. Natl Acad. Sci. 81, 3883-3887 (1984).

43. Goldstein, J. L., Ho, Y. K., Basu, S. K. \& Brown, M. S. Binding site on macrophages that mediates uptake and degradation of acetylated low density lipoprotein, producing massive cholesterol deposition. Proc. Natl Acad. Sci. 76, 333-337 (1979)

44. Bhakdi, S. et al. On the pathogenesis of atherosclerosis: enzymatic transformation of human low density lipoprotein to an atherogenic moiety. J. Exp. Med. 182, 1959-1971 (1995).

45. Klouche, M. et al. Enzymatically modified, nonoxidized LDL induces selective adhesion and transmigration of monocytes and T-lymphocytes through human endothelial cell monolayers. Arteriosclerosis Thrombosis Vasc. Biol. 19, 784-793 (1999).

46. Chellan, B., Reardon, C. A., Getz, G. S. \& Hofmann Bowman, M. A. Enzymatically modified low-density lipoprotein promotes foam cell formation in smooth muscle cells via macropinocytosis and enhances receptor-mediated uptake of oxidized low-density lipoprotein. Arterioscler Thromb. Vasc. Biol. 36, 1101-1113 (2016).

47. Armstrong, J. K., Wenby, R. B., Meiselman, H. J. \& Fisher, T. C. The hydrodynamic radii of macromolecules and their effect on red blood cell aggregation. Biophys. J. 87, 4259-4270 (2004).

48. Boyer, P. M. \& Hsu, J. T. Experimental studies of restricted protein diffusion in an agarose matrix. AIChE J. 38, 259-272 (1992).

49. Woollard, K. J. \& Geissmann, F. Monocytes in atherosclerosis: subsets and functions. Nat. Rev. Cardiol. 7, 77-86 (2010). 
50. Feaver, R. E., Gelfand, B. D. \& Blackman, B. R. Human haemodynamic frequency harmonics regulate the inflammatory phenotype of vascular endothelial cells. Nat. Commun. 4, 1525 (2013).

51. Huang, L. et al. SR-B1 drives endothelial cell LDL transcytosis via DOCK4 to promote atherosclerosis. Nature 569, 565-569 (2019).

52. Durafourt, B. A. et al. Comparison of polarization properties of human adult microglia and blood-derived macrophages. Glia 60, 717-727 (2012).

53. Palmer, E. M. \& van Seventer, G. A. Human T helper cell differentiation is regulated by the combined action of cytokines and accessory cell-dependent costimulatory signals. J. Immunol. 158, 2654-2662 (1997).

54. Murray, PeterJ. et al. Macrophage activation and polarization: nomenclature and experimental guidelines. Immunity 41, 14-20 (2014).

55. Park, Y. M. CD36, a scavenger receptor implicated in atherosclerosis. Exp. Mol. Med. 46, e99 (2014).

56. Kzhyshkowska, J., Neyen, C. \& Gordon, S. Role of macrophage scavenger receptors in atherosclerosis. Immunobiology 217, 492-502 (2012).

57. Alberts, A. W. Discovery, biochemistry and biology of lovastatin. Am. J. Cardiol. 62, J10-J15 (1988).

58. von Kugelgen, I. \& Hoffmann, K. Pharmacology and structure of P2Y receptors. Neuropharmacology 104, 50-61 (2016).

59. Kuang, Y. et al. The antagonist of P2Y11 receptor NF157 ameliorates oxidized LDL-induced vascular endothelial inflammation. Artif. Cells Nanomed. Biotechnol. 47, 1839-1845 (2019).

60. Linville, R. M. et al. Human iPSC-derived blood-brain barrier microvessels: validation of barrier function and endothelial cell behavior. Biomaterials 190191, 24-37 (2019).

61. van Duinen, V. et al. 96 perfusable blood vessels to study vascular permeability in vitro. Sci. Rep. 7, 18071 (2017).

62. Kapinsky, M. et al. Enzymatically degraded LDL preferentially binds to CD14high CD16+ monocytes and induces foam cell formation mediated only in part by the class B scavenger-receptor CD36. Arteriosclerosis Thrombosis Vasc. Biol. 21, 1004-1010 (2001).

63. Chiu, J. J. \& Chien, S. Effects of disturbed flow on vascular endothelium: pathophysiological basis and clinical perspectives. Physiol. Rev. 91, 327-387 (2011).

64. Gradinaru, D., Borsa, C., Ionescu, C. \& Prada, G. I. Oxidized LDL and NO synthesis-Biomarkers of endothelial dysfunction and ageing. Mech. Ageing Dev. 151, 101-113 (2015).

65. Zhao, L. \& Tackett, R. L. Oxidized low-density lipoprotein inhibits acetylcholine-induced vasorelaxation and increases 5-HT-induced vasoconstriction in isolated human saphenous vein. J. Pharmacol. Exp. Therapeutics 284, 637 (1998).

66. Cox, D. A. \& Cohen, M. L. Selective enhancement of 5-hydroxytryptamineinduced contraction of porcine coronary artery by oxidized low-density lipoprotein. J. Pharmacol. Exp. Therapeutics 276, 1095 (1996).

67. Nevala, R. et al. Dietary fatty acid composition influences the degree of human LDL oxidation, but has only minor effects on vascular tone in a bioassay system. Nutr. Metab. Cardiovasc. Dis. 10, 126-136 (2000).

68. Seppo, L. et al. A long-term fish diet modifies the toxic properties of human partially oxidized LDL on vascular preparations in vitro. J. Physiol. Pharmacol. 51, 251-265 (2000).

69. Moore, K. J., Sheedy, F. J. \& Fisher, E. A. Macrophages in atherosclerosis: a dynamic balance. Nat. Rev. Immunol. 13, 709-721 (2013).

70. Lhotak, S. et al. Characterization of proliferating lesion-resident cells during all stages of atherosclerotic growth. J. Am. Heart Assoc. 5, e003945 (2016).

71. Kang, S. D. et al. Isolation of functional human endothelial cells from small volumes of umbilical cord blood. Ann. Biomed. Eng. 41, 2181-2192 (2013).

72. Ghezzi, C. E. et al. An airway smooth muscle cell niche under physiological pulsatile flow culture using a tubular dense collagen construct. Biomaterials 34, 1954-1966 (2013).
73. Gong, M. M. et al. Human organotypic lymphatic vessel model elucidates microenvironment-dependent signaling and barrier function. Biomaterials 214, 119225 (2019).

74. Serpooshan, V., Quinn, T. M., Muja, N. \& Nazhat, S. N. Hydraulic permeability of multilayered collagen gel scaffolds under plastic compression-induced unidirectional fluid flow. Acta Biomater. 9 , 4673-4680 (2013).

75. Rumsey, S. C., Galeano, N. F., Arad, Y. \& Deckelbaum, R. J. Cryopreservation with sucrose maintains normal physical and biological properties of human plasma low density lipoproteins. J. Lipid Res. 33, 1551-1561 (1992).

\section{Acknowledgements}

This work was supported by NIH Grants UG3TR002142 and UH3TR002142 from NIAMS and NCATS, and R01HL138252. M.B. is supported on an NIH 1R38HL143612 01 fellowship. J.J.B. was supported by a fellowship from the Sarnoff Cardiovascular Research Foundation.

\section{Author contributions}

X.Z. and G.A.T. designed the project. X.Z. and G.A.T. developed the device. X.Z., G.Z., V.P., E.S., and J.J.B. performed the experiments and analysis. E.S. and Q.Z. isolated the ECs from blood. X.Z., M.B., and G.A.T. analyzed the data and co-wrote and edited the manuscript.

\section{Competing interests}

The authors declare no competing interests.

\section{Additional information}

Supplementary information is available for this paper at https://doi.org/10.1038/s41467020-19197-8.

Correspondence and requests for materials should be addressed to G.A.T.

Peer review information Nature Communications thanks Junichi Kawabe, Karlheinz Peter and the other, anonymous, reviewer(s) for their contribution to the peer review of this work. Peer reviewer reports are available.

Reprints and permission information is available at http://www.nature.com/reprints Publisher's note Springer Nature remains neutral with regard to jurisdictional claims in published maps and institutional affiliations.

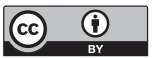

Open Access This article is licensed under a Creative Common Attribution 4.0 International License, which permits use, sharing, adaptation, distribution and reproduction in any medium or format, as long as you give appropriate credit to the original author(s) and the source, provide a link to the Creative Commons license, and indicate if changes were made. The images or other third party material in this article are included in the article's Creative Commons license, unless indicated otherwise in a credit line to the material. If material is not included in the article's Creative Commons license and your intended use is not permitted by statutory regulation or exceeds the permitted use, you will need to obtain permission directly from the copyright holder. To view a copy of this license, visit http://creativecommons.org/ licenses/by/4.0/.

(c) The Author(s) 2020 